\title{
Relevance of TNBS-Colitis in Rats: A Methodological Study with Endoscopic, Histologic and Transcriptomic Characterization and Correlation to IBD
}

\author{
Øystein Brenna ${ }^{1,2 *}$, Marianne W. Furnes ${ }^{2}$, Ignat Drozdov ${ }^{3}$, Atle van Beelen Granlund ${ }^{2}$, Arnar Flatberg ${ }^{2}$, \\ Arne K. Sandvik ${ }^{1,2}$, Rosalie T. M. Zwiggelaar ${ }^{2}$, Ronald Mårvik ${ }^{2,4}$, Ivar S. Nordrum ${ }^{2,5}$, Mark Kidd ${ }^{6}$, \\ Björn I. Gustafsson ${ }^{1,2}$
}

1 Department of Gastroenterology and Hepatology, St. Olavs Hospital, Trondheim University Hospital, Trondheim, Norway, 2 Department of Cancer Research and Molecular Medicine, Norwegian University of Science and Technology, Trondheim, Norway, 3 Bering Limited, Richmond, United Kingdom, 4 Department of Gastrointestinal Surgery, St. Olavs Hospital, Trondheim University Hospital, Trondheim, Norway, 5 Department of Pathology and Medical Genetics, St. Olavs Hospital, Trondheim University Hospital, Trondheim, Norway, $\mathbf{6}$ Department of Surgery, Section of Gastroenterology, Yale School of Medicine, New Haven, Connecticut, United States of America

\begin{abstract}
Background: Rectal instillation of trinitrobenzene sulphonic acid (TNBS) in ethanol is an established model for inflammatory bowel disease (IBD). We aimed to 1) set up a TNBS-colitis protocol resulting in an endoscopic and histologic picture resembling $I B D, 2)$ study the correlation between endoscopic, histologic and gene expression alterations at different time points after colitis induction, and 3) compare rat and human IBD mucosal transcriptomic data to evaluate whether TNBScolitis is an appropriate model of IBD.

Methodology/Principal Findings: Five female Sprague Daley rats received TNBS diluted in 50\% ethanol (18 mg/0.6 ml) rectally. The rats underwent colonoscopy with biopsy at different time points. RNA was extracted from rat biopsies and microarray was performed. PCR and in situ hybridization (ISH) were done for validation of microarray results. Rat microarray profiles were compared to human IBD expression profiles ( 25 ulcerative colitis Endoscopic score demonstrated mild to moderate colitis after three and seven days, but declined after twelve days. Histologic changes corresponded with the endoscopic appearance. Over-represented Gene Ontology Biological Processes included: Cell Adhesion, Immune Response, Lipid Metabolic Process, and Tissue Regeneration. IL-1 $\alpha$, IL-1 $\beta$, TLR2, TLR4, PRNP were all significantly up-regulated, while PPAR $\gamma$ was significantly down-regulated. Among genes with highest fold change (FC) were SPINK4, LBP, ADA, RETNLB and IL-1 $\alpha$. The highest concordance in differential expression between TNBS and IBD transcriptomes was three days after colitis induction. ISH and PCR results corresponded with the microarray data. The most concordantly expressed biologically relevant pathways included TNF signaling, Cell junction organization, and Interleukin-1 processing.

Conclusions/Significance: Endoscopy with biopsies in TNBS-colitis is useful to follow temporal changes of inflammation visually and histologically, and to acquire tissue for gene expression analyses. TNBS-colitis is an appropriate model to study specific biological processes in IBD.
\end{abstract}

Citation: Brenna $\varnothing$, Furnes MW, Drozdov I, van Beelen Granlund A, Flatberg A, et al. (2013) Relevance of TNBS-Colitis in Rats: A Methodological Study with Endoscopic, Histologic and Transcriptomic Characterization and Correlation to IBD. PLoS ONE 8(1): e54543. doi:10.1371/journal.pone.0054543

Editor: Benoit Foligne, Institut Pasteur de Lille, France

Received August 24, 2012; Accepted December 12, 2012; Published January 31, 2013

Copyright: (C) 2013 Brenna et al. This is an open-access article distributed under the terms of the Creative Commons Attribution License, which permits unrestricted use, distribution, and reproduction in any medium, provided the original author and source are credited.

Funding: Kontaktutvalget, St. Olavs Hospital, Trondheim University Hospital and DMF/NTNU (Project number 96990)(BIG); MK is supported by NIH DK080871; The microarray work was carried out with support from the National Technology Microarray Platform (Norwegian Microarray Consortium) funded the Functional Genomics Programme (FUGE) of the Norwegian Research Council. The funders had no role in study design, data collection and analysis, decision to publish, or preparation of the manuscript.

Competing Interests: The authors have the following interests. Ignat Drozdov is employed by Bering Limited and was paid was paid by NTNU as a consultant to do this work. Bering Limited was involved in data analysis. There are no patents, products in development or marketed products to declare. This does not alter the authors' adherence to all the PLOS ONE policies on sharing data and materials.

* E-mail: Oystein.Brenna@stolav.no

\section{Introduction}

Inflammatory bowel disease (IBD) is the common denomination of ulcerative colitis (UC) and Crohn's disease (CD). The etiology is unknown and the pathogenesis is complex and incompletely understood. The interplay between genetic and immunological host factors and the gut microbiota are important factors in the development of disease [1,2].
The inflammatory response in IBD is characterized by mucosal barrier dysfunction, microbial invasion and activation of immune response [3,4]. In genetically predisposed individuals, microbial activation via toll-like receptors (TLRs) and induction of an inflammatory response accompanied by high levels of proinflammatory cytokines such as interleukins (ILs) (IL-1, IL-6, IL13 and IL-17) and tumor necrosis factor alpha (TNF- $\alpha$ ), seem to be critical [1,5-9]. However, the exact molecular basis of IBD remains poorly understood. 


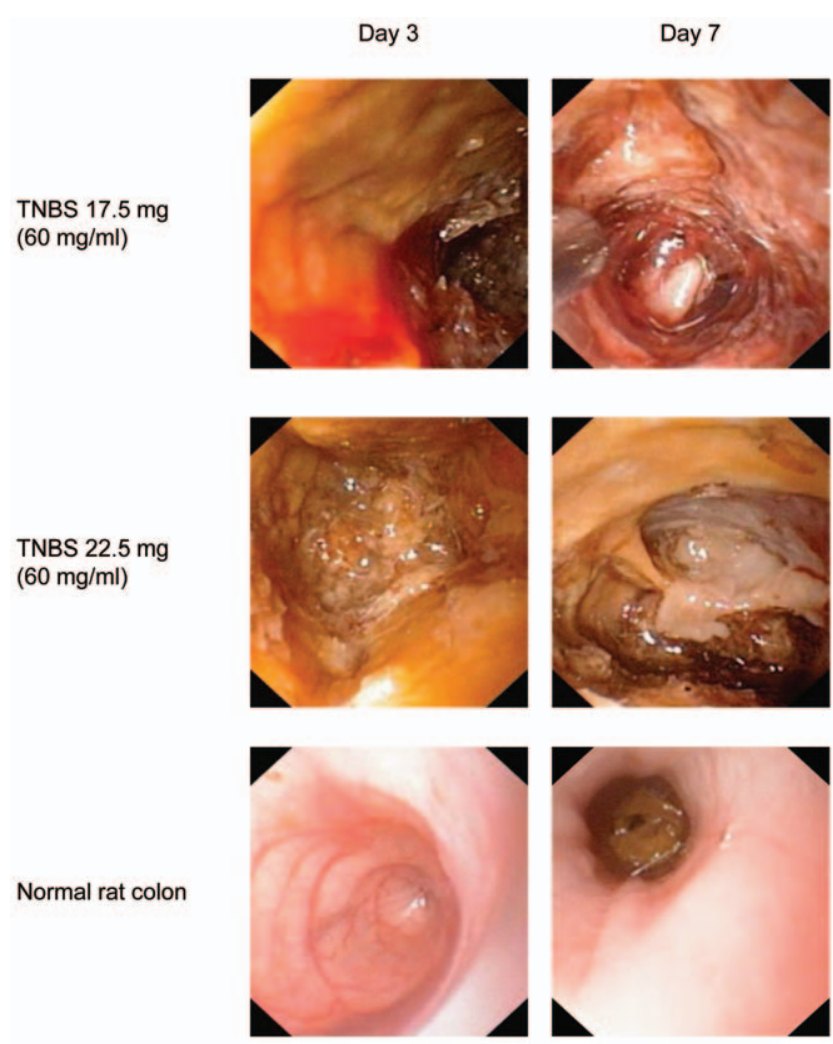

Figure 1. Endoscopic images demonstrating the effect of different doses of TNBS in a fixed concentration of $60 \mathrm{mg} / \mathrm{ml}$. Severe colitis with a yellowish membrane and coprostasis was noted at day 3 , and mucosal shedding, stenosis and necrosis was evident at day 7 in rats given TNBS $17.5 \mathrm{mg}$ and $22.5 \mathrm{mg}(0.29 \mathrm{ml}$ and $0.38 \mathrm{ml}$, respectively). The bottom panel depicts examples of normal rat colon. doi:10.1371/journal.pone.0054543.g001

Experimentally induced colitis with trinitrobenzene sulphonic acid (TNBS) is used to generate models that are used to examine the pathogenesis of gut inflammation, and determine the mechanisms and efficacy of therapies [10]. TNBS is diluted in ethanol which disrupts the mucosal barrier. Usually, the TNBSsolution is rectally instilled. Inflammation is induced by TNBSinduced haptenization of colonic mucosal proteins [11]. The use of TNBS to generate colitis was originally described and histologically characterized by Morris et al. in rats. Granulomas were observed in over $50 \%$ of animals two to three weeks after induction of colitis [12]. TNBS-ethanol administration is characterized by Th1-driven inflammation [11], and has primarily been regarded as a model for $\mathrm{CD}[10,13]$. The clinical features include weight loss and bloody diarrhea, while morphologically the model is characterized by mucosal, submucosal and transmural inflammation. Consequently, the model has been used to investigate the role and mechanistic action of drugs including 5-aminosalisylic acid, steroids and anti-tumor necrosis factor (TNF) in IBD [1416]. The administration and doses of TNBS differ significantly between studies; the methodology is inconsistent and no standardized protocol exists [14,17-20].

Both TNBS-colitis and IBD include disturbances in basic physiological processes like immune activation, metabolism and mucosal repair [21]. Microbial regulation of TLRs and induction of an inflammatory response is accompanied by regulation of proand anti-inflammatory cytokines and the shaping of the intestinal immune response [22]. Down-regulation of the peroxisome proliferator-activated receptor (PPAR) gamma involved in the regulation of fatty acid metabolism and inflammation, has been demonstrated in IBD and is associated with maintenance of defensin expression [23-25]. The cellular Prion protein $\left(\operatorname{PrP}^{\mathrm{c}}\right)$ is expressed in brain and various extra cerebral tissues including neuroendocrine cells and lymphoid tissue of the gut [26-28]. $\operatorname{PrP}^{\mathrm{c}}$ can have an anti-inflammatory effect in the colon [29].

We report the development and characterization of TNBScolitis in rats using colonoscopy and temporal gene expression profiling. The aim was to standardize TNBS administration to achieve a moderate inflammation. Achieving a moderate colitis allowed for the study of epithelial alterations upon mucosal damage, while temporal gene expression profiling identified longitudinal transcriptomic changes that were associated with these abnormalities. We further aimed to compare the genomewide changes in TNBS-colitis to a human transcriptome to determine whether TNBS at this dose was an appropriate model for IBD.

\section{Materials and Methods}

\section{Animals}

The study was approved by the National Animal Research Authority (NARA). The general care and use of the animals were in accordance with the European Convention for the protection of Vertebrate Animals used for Experimental and other Scientific purposes. We used female Sprague Dawley rats weighing 200$250 \mathrm{~g}$ from Taconic (Taconic Farms, Inc., Hallingore, Denmark). They were housed in individually ventilated cages (IVC) with aspen bedding (Tapvei) in a specific pathogen free (SPF) environment with temperature $19-22^{\circ} \mathrm{C}$ and humidity $50-60 \%$ and $12 \mathrm{hr}$ day and night cycle with $1 \mathrm{hr}$ dusk and dawn. All rats had access to water and standard chow (RM1 maintenance, SDS, UK) ad libitum, apart from the $24 \mathrm{hr}$ fasting periods before each colonoscopy to allow voiding of the left colon, when they had access only to glucose $2 \%$ fluid mixture and were kept in wired bottom cages. Rat colonoscopy was performed under general gas anesthesia using isoflurane. At termination, the rats were sacrificed by exsanguination during general isoflurane anesthesia.

\section{Initial studies and main study}

Initial studies to optimize TNBS dose and concentration. Sixteen rats weighing $264.9 \mathrm{~g}$ (standard deviation [SD] \pm 14.5 ) were divided into two groups. Group 1 received 17.5 and group 2 received $22.5 \mathrm{mg}$ TNBS $(1 \mathrm{M}, 293.17 \mathrm{mg} / \mathrm{ml}$, product number 92822, Fluka, Buchs, Switzerland) diluted in $50 \%$ ethanol to a concentration of $60 \mathrm{mg} / \mathrm{ml}$. The total volume instilled was $\sim 0.29 \mathrm{ml}$ and $\sim 0.38 \mathrm{ml}$ respectively for group 1 and 2 . In a subsequent study, eight rats received TNBS in eight different doses (7-31.5 mg) diluted in $50 \%$ ethanol, to a total volume of $0.7 \mathrm{ml}$ with concentrations ranging from $10-45 \mathrm{mg} / \mathrm{ml}$.

TNBS was rectally instilled via a female urinary catheter (DCT Ch 10, Servoprax GmbH, Wesel, Germany). After removal of residual rectal fecal pellets, the catheter was advanced approximately to the splenic flexure. After instillation, the rats were held with the head down for one minute to prevent TNBS from leaking out. The colitis was evaluated with colonoscopy (Olympus ureterorenoscope, URF Type V) with picture documentation at Day 3, Day 7 and at Day 12. Biopsies were obtained using an Olympus biopsy forceps (FB-56 D-1, Olympus, Norway).

Main study. Eight female Sprague Dawley rats, age eight weeks and weighing $196.9 \mathrm{~g}(\mathrm{SD} \pm 14.3)$ were used. Based on the initial studies, TNBS dissolved in $50 \%$ ethanol to a concentration of $30 \mathrm{mg} / \mathrm{ml}$ in a total volume of $0.6 \mathrm{ml}$ was instilled. Animal 
Day 3
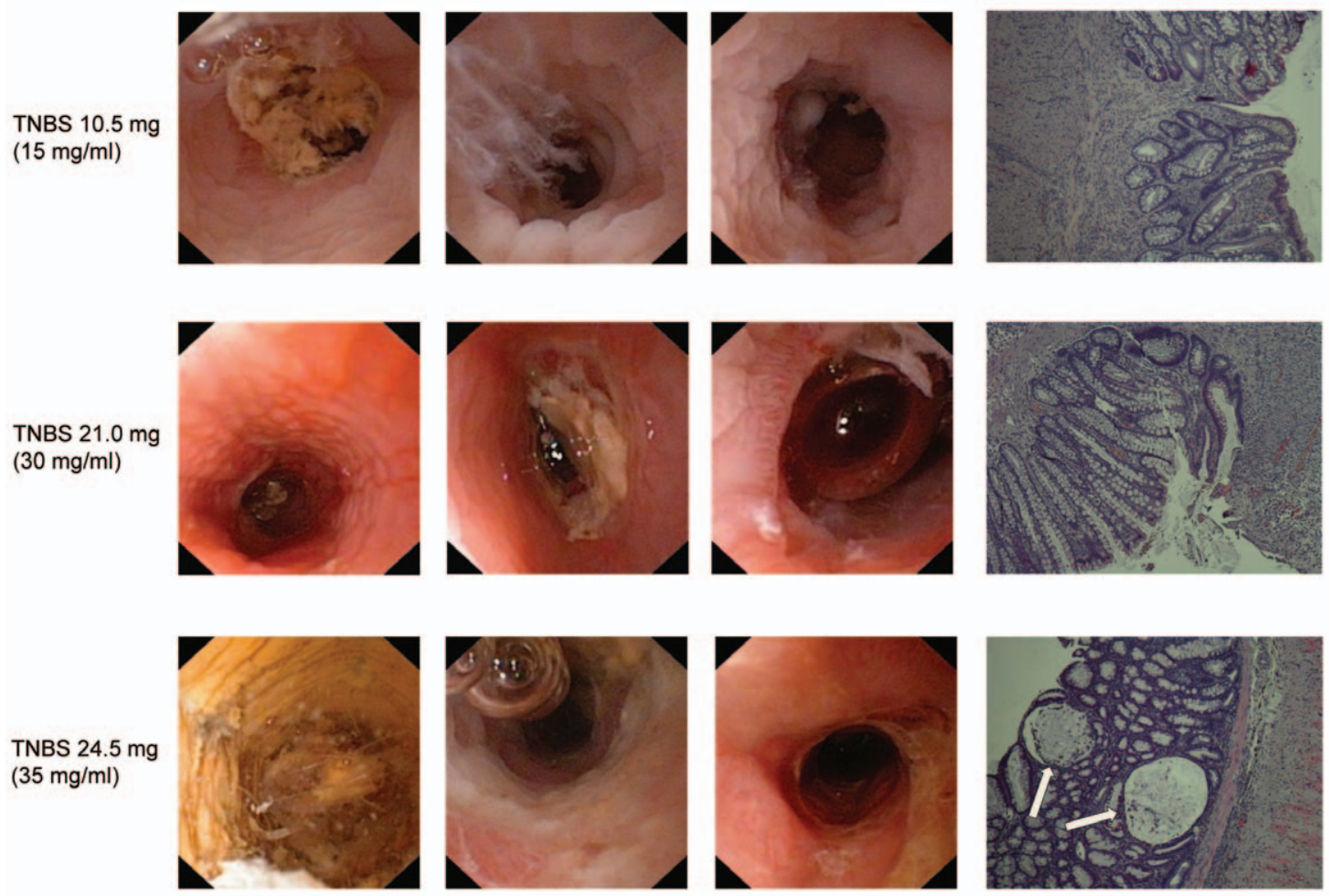

TNBS $24.5 \mathrm{mg}$ $(35 \mathrm{mg} / \mathrm{ml})$

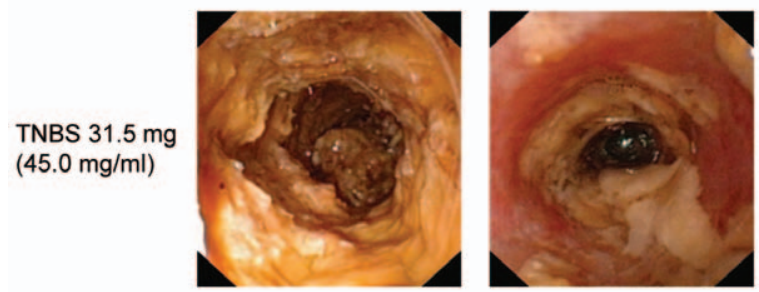

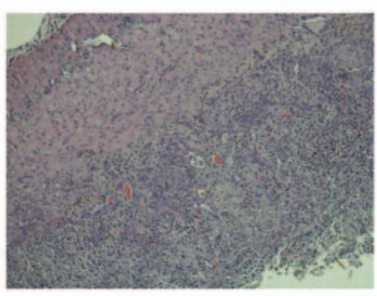

Figure 2. Endoscopic images demonstrating the effect of TNBS at different concentrations instilled rectally in a total volume of $0.7 \mathrm{ml}$. TNBS $10.5 \mathrm{mg}(15 \mathrm{mg} / \mathrm{ml})$ was associated with minimal mucosal inflammation and edema. TNBS $21.0 \mathrm{mg}(30 \mathrm{mg} / \mathrm{ml}) \mathrm{resulted}$ in an erythematous and edematous mucosa at day 3 and 7. At day 12 mucosal granulation and ulcerations were seen. TNBS $24.5 \mathrm{mg}(35 \mathrm{mg} / \mathrm{ml})$ and $31.5 \mathrm{mg}(45 \mathrm{mg} / \mathrm{ml})$ resulted in a more severe acute inflammation, and at day 7, larger areas of ulceration with fibrin cover were visible. At day 12 , stenotic strictures developed in the rat receiving TNBS $24.5 \mathrm{mg}$. The rat receiving $31.5 \mathrm{mg}$ was euthanized after the second endoscopy and consequently no endoscopic picture from day 12 can be shown. In the right column, histological pictures corresponding to mild, moderate and severe TNBS-colitis are included. TNBS $10.5 \mathrm{mg}(15 \mathrm{mg} / \mathrm{ml})$ resulted in only minimal inflammation with some architectural changes. TNBS $21.0 \mathrm{mg}$ $(30 \mathrm{mg} / \mathrm{ml})$ resulted in ulceration that bordered the mucosa with inflammatory cell infiltration. In TNBS $24.5 \mathrm{mg}$ ( $35 \mathrm{mg} / \mathrm{ml})$, crypt distortion and abscesses (arrows) with mucosal and submucosal inflammatory infiltration were visible. Severe TNBS colitis is seen in the lower hitstologic picture with transmural inflammatory cell infiltration and total denudation of the mucosa. Objective $\mathrm{x} 10$ in all histological images.

doi:10.1371/journal.pone.0054543.g002

weights and clinical status were monitored throughout the study. Colonoscopy with photo documentation and tissue sampling was performed two days before (T0), and three (T3), seven (T7) and twelve (T12) days after induction of colitis. A modified Murine Endoscopic Index of Colitis Severity [30] (MEICS, 0-12, Thickening of the colon was not considered) was used for endoscopic evaluation and grading of the colitis. Five animals that developed similar endoscopically moderate colitis in the left colon were chosen for further studies.

During each colonoscopy, three biopsies were collected and snap frozen in liquid nitrogen for later RNA extraction. Another two biopsies were fixed in $4 \%$ buffered formaldehyde and then embedded in paraffin. The study was terminated at T12. The colon was divided longitudinally and one part fixed in formalde- hyde for histologic examination and the other frozen in liquid nitrogen.

Animal weight data were compared using Student's t-test with equal variances after confirming this with f-test. The significance level was set at $\alpha=0.05$.

RNA extraction, microarray amplification, hybridization, scanning and quantification

Rat mucosal samples. From each animal, three biopsies were collected at every time point in the main study (TNBS $30 \mathrm{mg} / \mathrm{ml}, 0.6 \mathrm{ml}$ ). Samples were pooled and RNA was extracted using the RNeasy Mini RNA extraction Kit (cat.no. 74106, Qiagen, Hilden, Germany) according to the manufacturer's protocol. Quality of extracted RNA was controlled using 
A

Rat 1

Rat 4

Rat 5
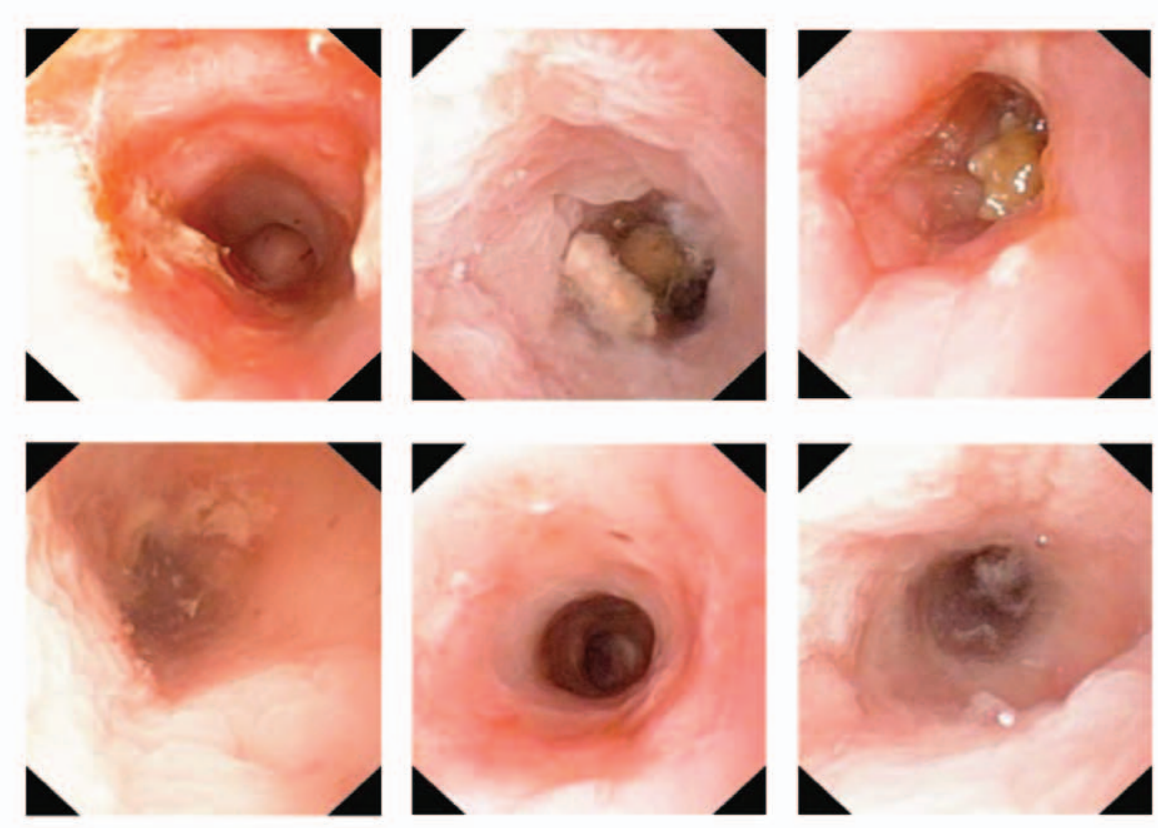

$\mathbf{1}$
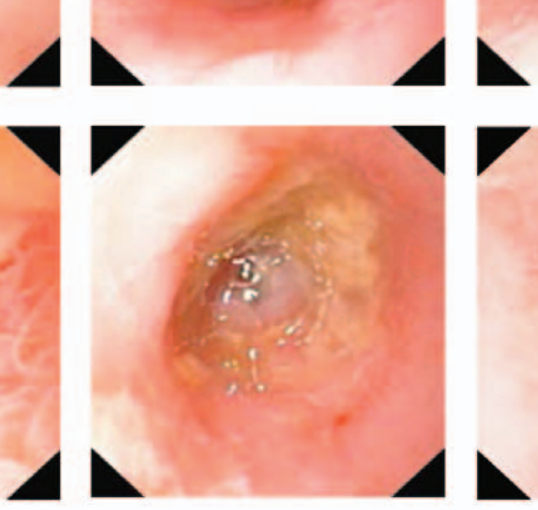

B

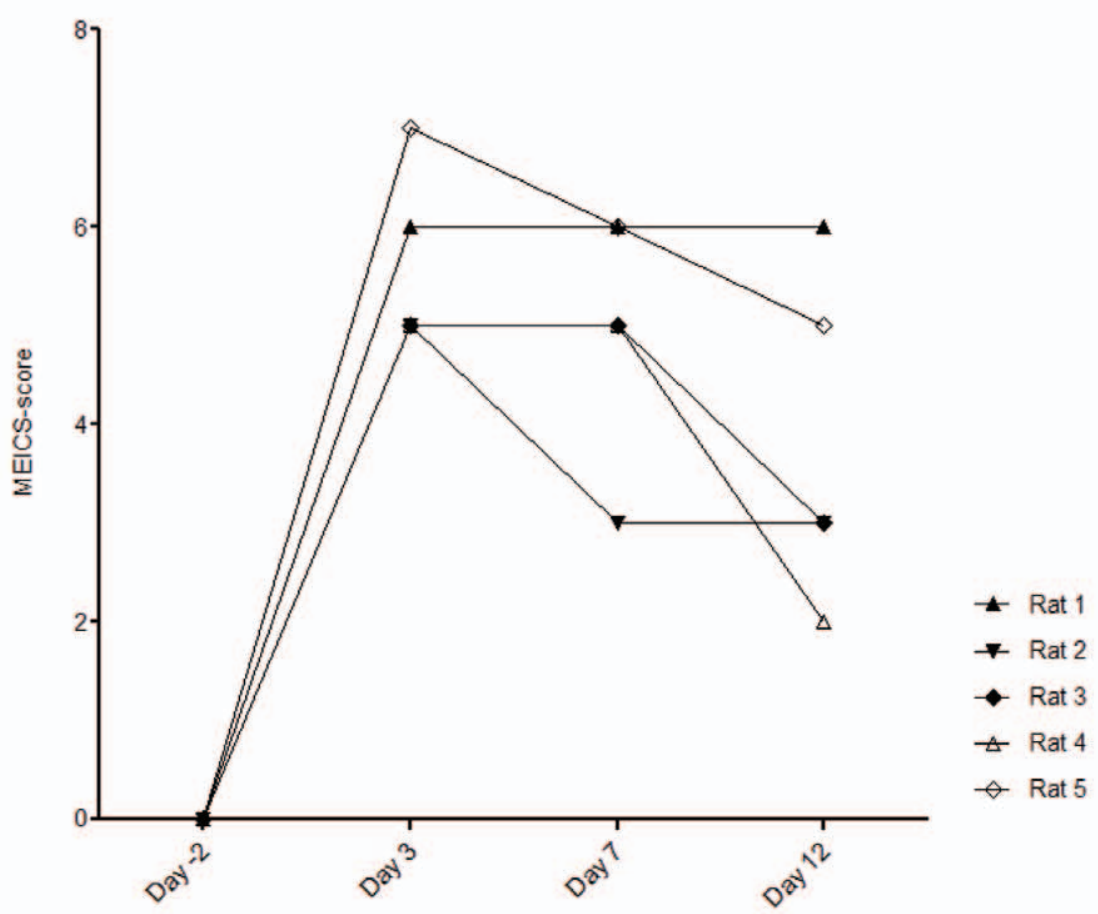


Figure 3. Representative endoscopic images of TNBS $(30 \mathrm{mg} / \mathrm{ml}, 0.6 \mathrm{ml})$ associated changes at different time points and MEICSscore at T0, T3, T7 and T12. (A) Granulated and edematous mucosa at T3 and T7, and ulcerations at T12 were evident in Rat 1 . At T7, small ulcerations/erosions were identified in Rat 4. In Rat 5, an ulceration is visible at T7 and at T12, a stricturing ulcer has developed. (B) The MEICS-score at T3 was significantly different from $\mathrm{T} 12(p=0.02)$.

doi:10.1371/journal.pone.0054543.g003

NanoDrop Spectrophotometer (Thermo Scientific, DE, USA) and Bioanalyzer (Agilent Technologies, CA, USA). Samples with RIN $>7$ were deemed suitable for downstream analysis. Biotinylated cRNA was prepared from $400 \mathrm{ng}$ RNA for each sample using the Illumina TotalPrep RNA Amplification kit (Applied Biosystems/Ambion, Austin, TX, USA). Sample cRNA was subsequently hybridized on Illumina human RatRef-12 v1 expression BeadChips (Illumina, San Diego, CA, USA) and scanned on an Illumina BeadStation. Data from this analysis is publicly available at ArrayExpress, E-MTAB-1263.

Human mucosal samples. Gene expression profiles in mucosal samples from 25 patients with UC, 11 patients with $\mathrm{CD}$, and 25 healthy controls were used for comparison with the

A

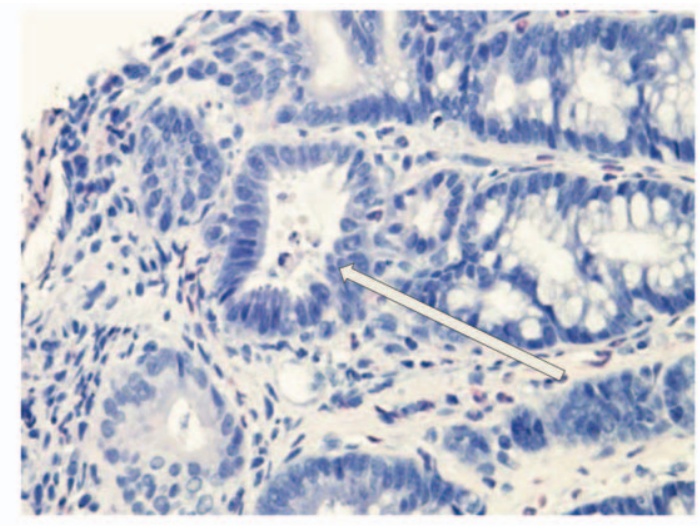

B

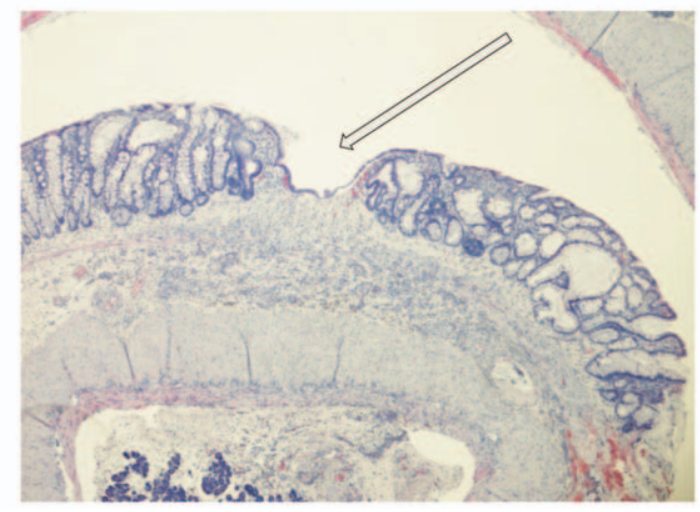

Figure 4. Histologic appearance of an endoscopic biopsy and whole colon specimen. (A) Endoscopic biopsy collected at T7 showing evidence of a crypt abscess (arrow), and mucosal gland distortion. Objective $x 40$. (B) Histologic image of a whole colon specimen collected at termination of the study (T12) identifying distorted mucosal glands, and an ulceration with completed reepithelialization and underlying submucosal inflammation (arrow). Objective $x 4$. The slides were stained with hematoxylin and eosin. doi:10.1371/journal.pone.0054543.g004
TNBS-transcriptomes. The data used was drawn from a larger IBD gene expression analysis study performed at Norwegian University of Science and Technology/St. Olavs Hospital, Trondheim, Norway. All IBD samples were obtained from maximally inflamed colonic mucosa, while normal controls were taken from the hepatic flexure. Four endoscopic pinch biopsies were collected from each area. Three biopsies were immediately snap frozen in liquid nitrogen, while the remaining sample was fixed in $4 \%$ buffered formaldehyde. The formaldehyde-fixed samples were embedded in paraffin and $4 \mu \mathrm{m}$ sections were cut and stained with hematoxylin-eosin for histological evaluation by an experienced pathologist. In cases where the evaluation differed from the macroscopic observations, samples were removed from the analysis. Frozen biopsies were homogenized using an UltraTurrax T 25 homogenizer (Zanke \& Kunkel IKA-Laboratorie Technik, Staufen, Germany). Total RNA was extracted using Ambion mirVana ${ }^{\mathrm{TM}}$ miRNA Isolation Kit (Applied Biosystems, Foster City, CA, USA). RNA quantity, purity and integrity were assessed using a NanoDrop ${ }^{\text {TM }}$ Spectrophotometer (Thermo Scientific, Wilmington, DE, USA) and Bioanalyzer (Agilent Technologies, Santa Clara, CA, USA). Only samples with a RIN $>7$ were used in the subsequent microarray analysis. For each sample, $250 \mathrm{ng}$ total RNA was used to generate biotinylated, amplified cRNA following the Illumina TotalPrer RNA Amplification Kit (Applied Biosystems/Ambion, Austin, TX, USA). The samples were hybridized on Illumina HT12 expression BeadChips (Illumina, San Diego, CA, USA) and scanned on an Illumina BeadStation. Informed written consent was obtained from all involved patients, and the study was approved by the Regional Medical Research Ethics Committee (approval no 5.2007.910). The study was registered in the Clinical Trials Protocol Registration System (identifier NCT00516776). Data from this analysis is publicly available at ArrayExpress, E-MTAB-184.

\section{Data preparation and bioinformatic analysis}

Gene expression analysis. Raw data was exported from the Illumina GenomeStudio software and normalized using the lumi package for Bioconductor suite [31]. The data was quantile normalized and $\log 2$ transformed. Time course differential gene expression analysis was performed using the BETR package for $\mathrm{R}$ statistical environment [32]. Pairwise group comparisons were performed using a Student's t-test. The (FG) was used to express the changes in average gene expressions between studied groups. To standardize annotation across microarray platforms, Illumina probe identifiers were mapped to their corresponding Ensembl (accessed March 23, 2011) gene identifiers (IDs) [33].

Clusters of similar gene expression profiles were identified using the Affinity propagation (AP) algorithm [34], where dissimilarity was expressed as the negative Euclidian distance. Subsequently, gene clusters were enriched for over-represented Gene Ontology (GO) Biological Process (BP) terms [35] using the hypergeometric test. For a cluster with $n$ genes and an a priori defined functional category with $K$ genes, the hypergeometric test was used to evaluate the significance of overlap $k$ between the cluster and GOBP category [36,37]. All $\mathcal{N}$ genes on a microarray were used as reference. To ensure specificity of annotation within a gene cluster, functional categories containing $<5$ or $>1000$ genes were removed. 


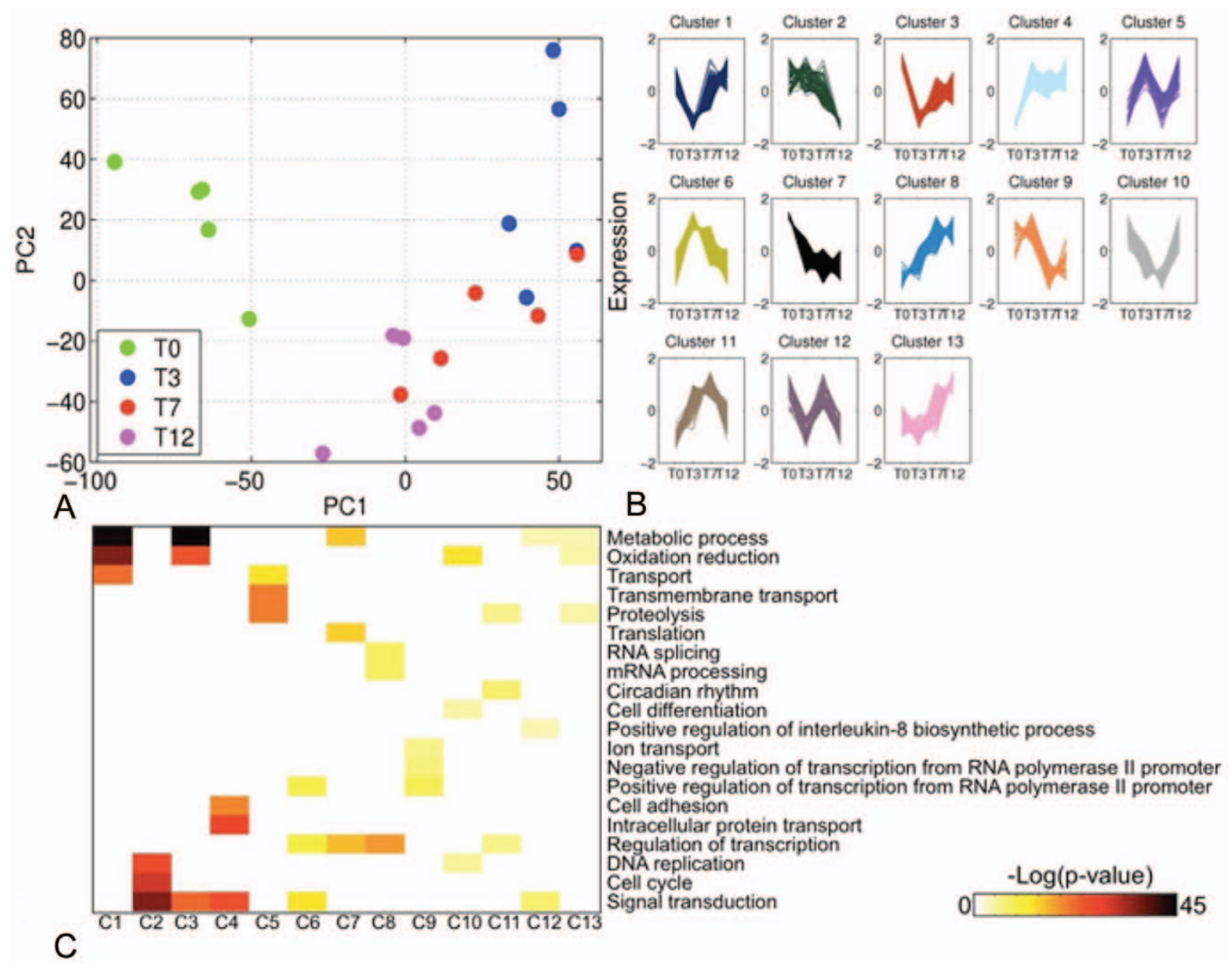

Figure 5. Differential expression analysis of the TNBS transcriptome. (A) Scatter plot of the Principal Component Analysis of 8316 genes in response to TNBS. (B) Expression profiles of genes assigned to the 13 clusters of similar expression (see Table S1). Only differentially expressed genes are included. (C) Heat map visualizing functional enrichment of the 13 clusters for over-represented Gene Ontology Biological Process terms. Darker shades represent a greater degree of enrichment. doi:10.1371/journal.pone.0054543.g005

\section{Comparison of TNBS to IBD transcriptomes}

Concordance between TNBS-colitis and IBD transcriptomes was assessed at the level of individual gene loci as well as at the level of KEGG [38] and Reactome pathways [39]. To standardize comparisons between rat and human data, rat gene Ensembl IDs were mapped to respective human orthologs. In total, 6142 genes were considered. TNBS-colitis FCs were calculated by comparing gene expression profiles at T3, T7, and T12 to T0. Similarly, IBD FGs were computed by comparing $\mathrm{CD}$ and $\mathrm{UC}$ samples to normal (N) tissue. At the level of single gene loci, concordance tests were carried out by correlating FCs of the TNBS-colitis and IBD transcriptomes. Gene expression profiles with Student's t-test $p<0.05$ and absolute $\log 2 \mathrm{FC} \geq 1.1$ were considered differentially regulated.

To assess concordance at the level of biological pathways, gene expression FGs in TNBS-colitis and IBD transcriptomes were mapped to respective Reactome and KEGG pathways. To ensure that only well-characterized cascades were studied, pathways with fewer than 5 genes were excluded. Subsequently, a pathway-level FC was computed by averaging FCs of all genes that mapped to a specific pathway. Finally, TNBS-colitis and IBD pathway level FCs were correlated.

For all comparisons, Spearman's rho was used to estimate correlations between TNBS-colitis and IBD FCs. Respective $p$ values were computed for testing the hypothesis of no correlation against the alternative that there is a nonzero correlation and $p<0.05$ was called statistically significant. Analysis was performed using the Statistics toolbox for Matlab (2009a, The MathWorks, Natick, MA, USA).

\section{Candidate genes}

Interleukin 1 alpha (IL- $1 \alpha$ ) and interleukin 1 beta (IL-1 $\beta$ ) were chosen as general markers of inflammation. TLR2 and TLR4 were considered markers of bacterial regulation of inflammatory responses. In addition, based on the degree of regulation and statistical significance, genes encoding the peroxisome proliferatoractivated receptor gamma $(\mathrm{PPAR} \gamma)$ and the endogenous prion protein $\left(\mathrm{PRNP}\left[\mathrm{PrP}^{\mathrm{C}}\right]\right.$ ) were further evaluated. 

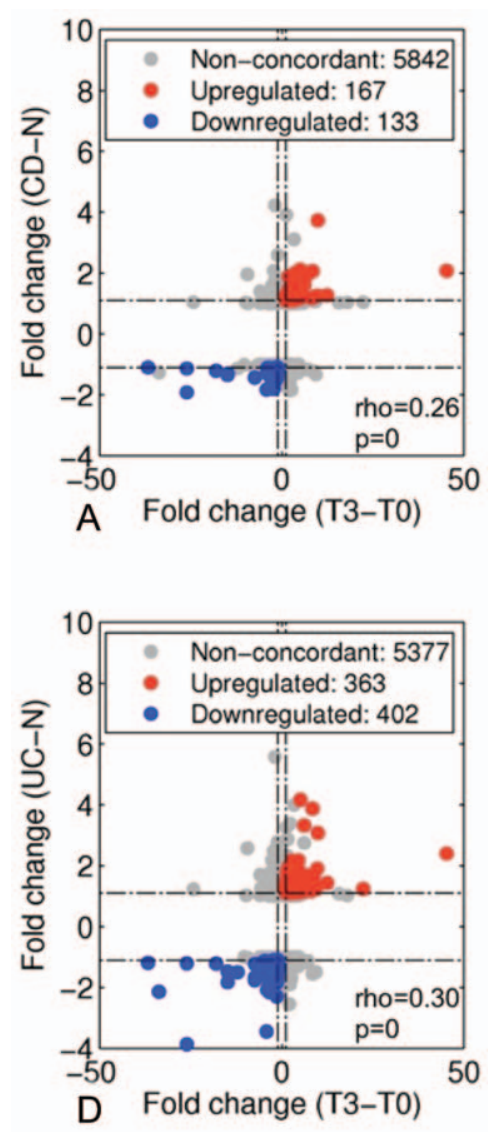

Figure 6. Concordance analysis between TNBS-colitis and IBD transcriptomes at the level of single gene loci. $T 3 \mathrm{vs} . T 0, T 7 \mathrm{vs}$. TO and $T 12$ vs. TO compared to $C D$ vs. normal (top) and UC vs. normal (bottom). (A-F) Scatterplots of FCs in rat data (x-axis) compared to FCs in the human data (y-axis). Rho values correspond to Spearman correlation coefficients with $p$-values representing the level of significance of the correlation. Concordant up- and down-regulated genes are represented as red and blue circles respectively. Nonconcordant genes are shown as grey circles. Numbers in the legend correspond to the total number of genes assigned to each category. B, $\mathrm{C}, \mathrm{E}$ and $\mathrm{F}$ are only shown in the supplemental section (Figure S1). doi:10.1371/journal.pone.0054543.g006

\section{Histological evaluation}

Endoscopic biopsies and whole colon specimens were fixed in $4 \%$ buffered formaldehyde, placed in standard plastic briquettes for tissue specimens and processed via standard protocols (dehydration, clearing and paraffinization overnight). Sections from each block were cut in $4 \mu \mathrm{m}$ thickness and stained with hematoxylin-eosin. The slides were examined by a surgical pathologist (ISN) and the degree and type of inflammation, ulceration and degree of regeneration/architectural distortion was assessed.

\section{In situ hybridization}

In situ hybridization (ISH) on endoscopic biopsies was performed using RNA-probes for the following genes: IL- $1 \alpha$ (NM_017019), IL-1 $\beta$ (NM_031512), TLR2 (NM_198769), TLR4 (NM_019178), PPAR $\gamma \quad$ (NM_001145367) and PRNP (NM_012631) with the RNAscope ${ }^{\circledR} 2.0$ assay kit (Advanced Cell Diagnostics Inc., Hayward CA, USA.), according to the manufacturer's protocol. Briefly, endoscopic biopsies were fixed in 4\% buffered formaldehyde for five days and embedded in paraffin.
Sections from each block were cut in $4 \mu \mathrm{m}$ thickness and baked $1 \mathrm{hr}$ at $60^{\circ} \mathrm{C}$ prior to use. After de-paraffinization and dehydration, the biopsies were air dried and treated with peroxidase blocker before gentle boiling in a pretreat solution for $15 \mathrm{~min}$. Then, protease was applied for $30 \mathrm{~min}$ at $40^{\circ} \mathrm{C}$. After pretreatment steps, the target probe was applied and hybridized for $2 \mathrm{hr}$ at $40^{\circ} \mathrm{C}$. Thereafter, the amplification steps including application of a horseradish peroxidase (HRP)-linked labeling probe were performed prior to DAB-visualization.

PCR

RNA from 18 biopsies (no residual RNA was available from rat 2 and 4 at T3 and T7, respectively), was converted to cDNA with High Capacity RNA-to-cDNA Kit (Applied Biosystems, Foster City, CA, USA) according to the manufacturer's manual. PCR was performed using TaqMan ${ }^{\circledR}$ Array Plates (Life Technologies $^{\text {TM }}$, Carlsbad, CA, USA) on a Step One Plus ${ }^{\text {TM }}$ Real Time PCR System. Genes with the largest FG alteration in the microarray data, serine peptidase inhibitor of the Kazal type 4 (SPINK4), adenosine deaminase (ADA), and fatty acid binding protein (FABP) 1 were analyzed. Actin beta (ACTB) was used as housekeeping gene. For each time point relative differential expression was calculated using the ddCT method followed by two-tailed paired t-test, T0 served as control.

\section{Results}

\section{Optimization of the TNBS protocol}

In order to standardize the TNBS-protocol to achieve a moderate colitis, we initially instilled TNBS in two doses (17.5 and $22.5 \mathrm{mg}$ ) at a fixed concentration of $60 \mathrm{mg} / \mathrm{ml}$. The inflammation was severe in seven out of 16 rats in both treatment

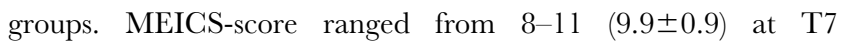
(Figure 1). The study had to be terminated prematurely for animal welfare reasons.

The protocol was adjusted and TNBS was administered in different concentrations and a fixed volume of $0.7 \mathrm{ml}$. TNBS concentrations of $10 \mathrm{mg} / \mathrm{ml}$ and $15 \mathrm{mg} / \mathrm{ml}$ resulted in only slight endoscopic and histologic inflammation. Mucosal erythema and edema and histologic submucosal inflammation without ulcerations were seen at a TNBS concentration of $20 \mathrm{mg} / \mathrm{ml}$. TNBS at $25-40 \mathrm{mg} / \mathrm{ml}$ resulted in mucosal edema and friability. Histologic examination revealed ulcerations and submucosal inflammation. TNBS $30 \mathrm{mg} / \mathrm{ml}$ induced a moderate inflammation with MEICSscore 7 and 5 at day 3 and day 7 , respectively. The highest TNBS concentration $(45 \mathrm{mg} / \mathrm{ml})$ induced severe colitis with general weakening and the rat was therefore euthanized at day 7 (Figure 2).

The protocol optimization demonstrated that $0.7 \mathrm{ml}$ of TNBS $(30 \mathrm{mg} / \mathrm{ml})$ induced a moderate colitis that lasted at least 12 days and declined between T7 and T12. However, a small fraction of TNBS tended to leak from the rectum immediately after instillation. The total volume was therefore reduced to $0.6 \mathrm{ml}$ for the subsequent study.

\section{Characterization of moderate TNBS-colitis}

Five animals treated with TNBS $30 \mathrm{mg} / \mathrm{ml}(0.6 \mathrm{ml})$ developed moderate colitis from the splenic flexure down to the recto-sigmoid junction. The MEICS-score peaked at T3 (5.6 \pm 0.9 , T3 vs. T12, $p=0.02)$ and T7 (5.0 1.2 , T7 vs. T12, $p=0.11)$ (Figure 3A and B). An acute weight loss occurred at T3 (196.7 $\pm 14.3 \mathrm{~g}$ at T0 versus $187.6 \pm 17.3 \mathrm{~g}$ at $\mathrm{T} 3$, mean weight loss $9.3 \mathrm{~g}, 4.7 \%$, $p=0.003)$. The animal weights recovered to $200.4 \pm 24.7 \mathrm{~g}$ and 209.4 $\pm 19.2 \mathrm{~g}$ at T7 and T12, respectively. Loose and bloody stools were noticed in two rats. Signs of cryptitis and architectural 

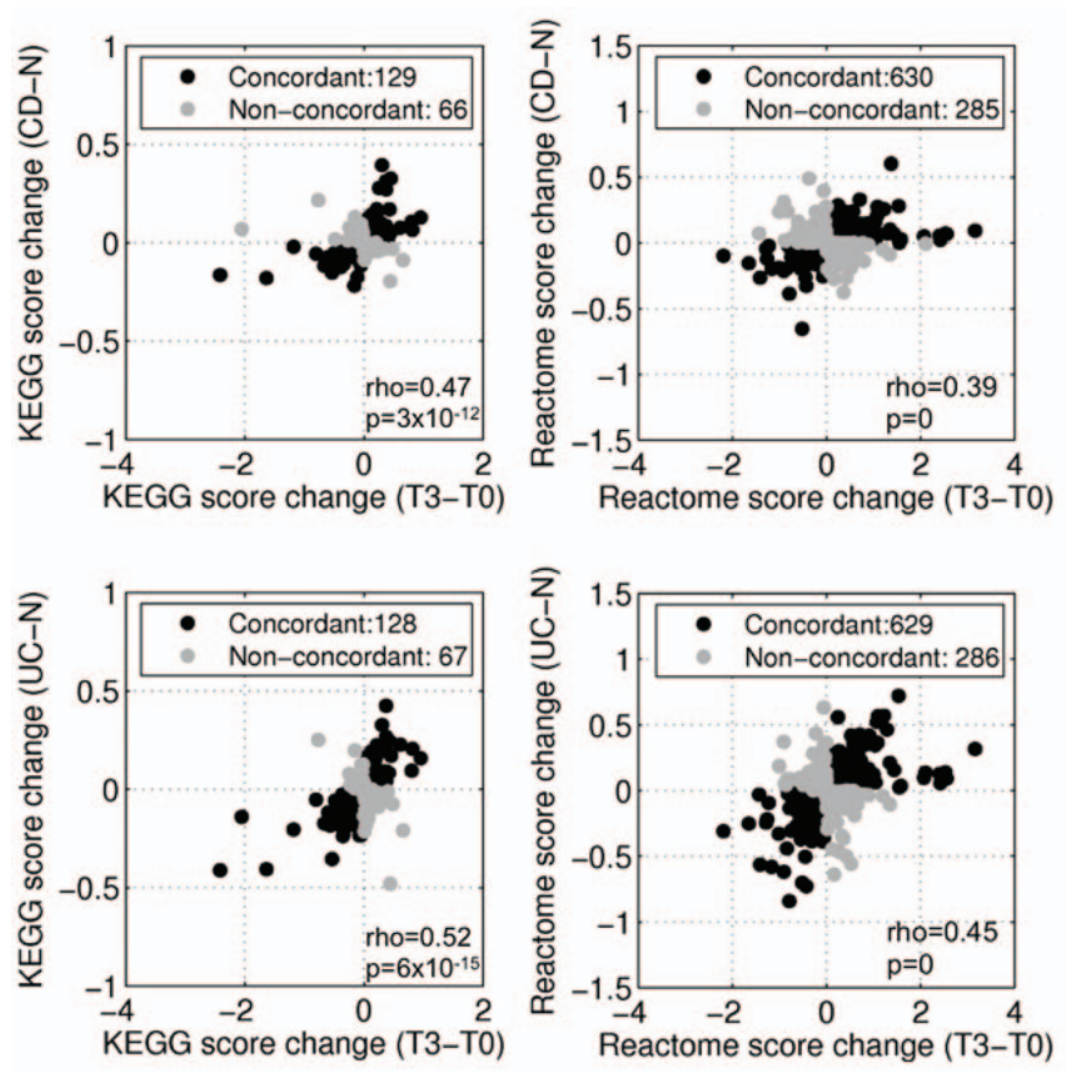

Figure 7. Concordance analysis between TNBS-colitis and IBD transcriptomes at the level of biological pathways. T3 vs. TO compared to CD vs. normal (top) and UC vs. normal (bottom). Left, scatter plots of pathway activity scores of KEGG pathways in TNBS and IBD samples. Right, scatter plots of pathway activity scores of Reactome pathways in TNBS and IBD samples. Rho values correspond to Spearman correlation coefficients with $p$-values representing the level of significance of the correlation. Numbers in the legend correspond to the total number of pathways assigned to each category. A similar figure (Figure S2) for concordant analysis of $T 7 \mathrm{vs.} T 0$ and $T 12$ vs. TO, compared to CD vs. normal and UC vs. normal is shown in the supplementary section (KEGG and Reactome score change at the top and bottom, for T7 vs. T0 and T12 vs. T0, respectively). doi:10.1371/journal.pone.0054543.g007

distortion were seen in endoscopic biopsies, whereas histologic examination of whole colon specimens at T12 demonstrated regenerative changes, ulcerations and transmural inflammation (Figure $4 \mathrm{~A}$ and $\mathrm{B}$ ).

\section{Temporal TNBS-colitis gene expression analysis}

Gene expression profiling of biopsies collected at time-points T0, T3, T7 and T12 was undertaken. After microarray preprocessing, expression profiles of 8316 genes were reduced to two Principal Components (PCs) to visualize differences in gene expression due to TNBS-induced inflammation (Figure 5A). Colitis induction resulted in distinct gene expression profiles while inter-individual temporal changes due to TNBS were not obvious.

To identify genes with sustained differential expression across all time points, the BETR algorithm was used. Genes with differential expression probabilities $>0.99$ were called significant. This analysis returned 3414 significantly regulated genes, which were subsequently clustered using the AP algorithm (Figure 5B). Significantly regulated genes were allocated to 13 clusters, with 588 and 63 genes assigned to the largest and smallest clusters, respectively. The full list of gene cluster assignments can be accessed in supplementary Table S1. Functional cluster enrichment for over-represented GO-BP terms identified processes such as Oxidation reduction (Clusters 1 and 3), Cell cycle (Cluster 2) and Cell adhesion (Cluster 4) (Figure 5C).

\section{Comparison of the TNBS and IBD transcriptomes}

To quantitate the similarity between the TNBS and IBD transcriptomes, differentially expressed genes at T3, T7 and T12 were compared to differentially expressed genes in $\mathrm{CD}$ and UC. Overall, 6142 rat genes could be mapped to human orthologs. The highest concordance was observed between $\mathrm{CD}$ and T3 (rho $=0.26, \quad \mathrm{p}=0 ; n=300$ significantly regulated concordant genes) (Figure 6A). Similarly, the most concordance in differential expression was found between $\mathrm{UG}$ and T3 (rho $=0.30, \mathrm{p}=0$; $n=765$ significantly regulated concordant genes) (Figure 6D). Up-regulated genes in both TNBS-colitis and human IBD included $\mathrm{ADA}, \operatorname{PrP}^{\mathrm{c}}$, and IL-1 $\alpha$, while down-regulated genes consisted of aldehyde dehydrogenase 1 family, member Al (ALDH $1 \mathrm{Al}$ ), and PPAR $\gamma$. A full list of comparable gene changes in TNBS-colitis compared to $\mathrm{CD}$ and $\mathrm{UC}$ is available as supplementary Table S2.

As disruption in single gene expression can affect behavior of molecular pathways [40], concordance between the TNBS model and IBD was also assessed at the level of biological pathways. To ensure that results reflected a real phenomenon rather than a database-specific result, the FCs in gene expression were mapped to their respective identifiers in the KEGG $(n=195$ pathways) and Reactome ( $n=915$ pathways) pathway databases. The highest concordance between $\mathrm{CD}$ and TNBS-colitis was observed at T3 $\left(\right.$ KEGG: Rho $=0.47, \mathrm{p}=3 \times 10^{-12}$, Reactome: $\mathrm{Rho}=0.39, \mathrm{p}=0$ ) (Figure 7). Concordant pathways included Reactome pathways 
A

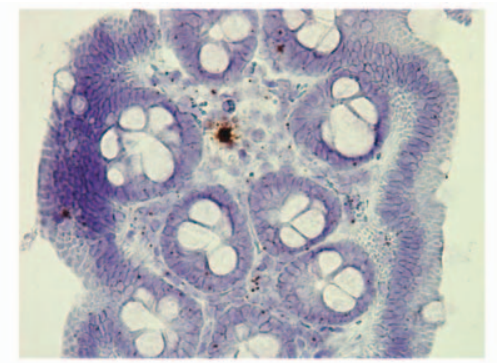

TLR2

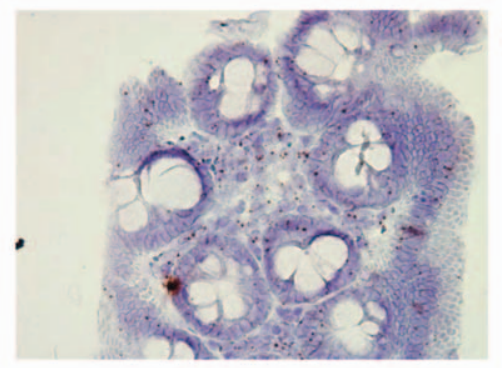

E

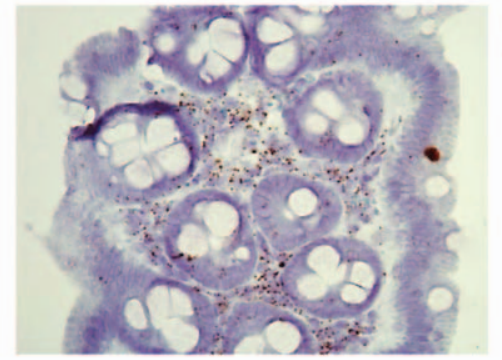

G

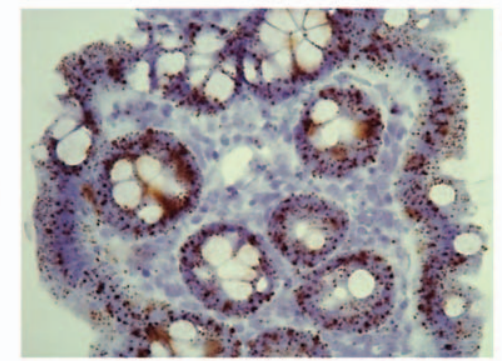

B

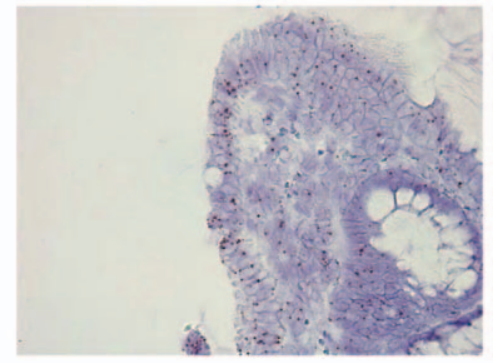

D

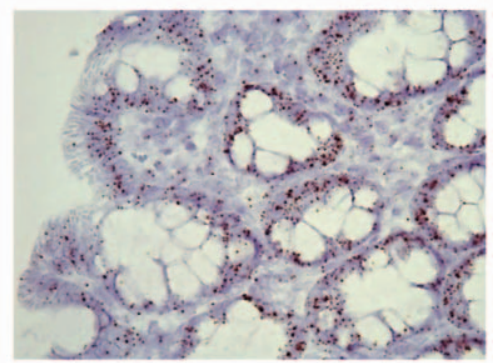

$\mathrm{F}$

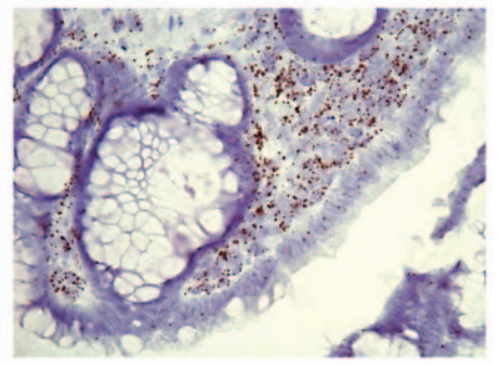

$\mathrm{H}$

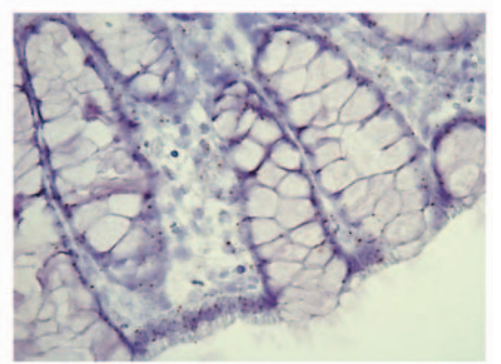

Figure 8. In situ hybridization (ISH) of significantly regulated genes in TNBS colitis mucosal biopsies. (A and C) The expression of TLR2 and TLR4 is scattered in the epithelium and submucosal immune cells at TO. (B and D) Increased TLR2 and TLR4 expression was noted in the epithelium at T7. (E) PRNP expression in submucosal immune cells at T0. (F) Intense PRNP expressing cells were evident in the submucosa at T12 and also to some degree in the epithelium. (G) Intense clusters of PPAR $\gamma$ expression in epithelial cells at T0. (H) At T12, the expression is almost abolished. Objective $\mathrm{x} 40$ in all pictures.

doi:10.1371/journal.pone.0054543.g008

such as Apoptosis, Cell junction organization, Interleukin-1 processing; nonconcordant pathways included GABA-A receptor activation, Extrinsic pathways for apoptosis and Recycling of bile acids and salts. Similarly, the most concordance was noted between UG and T3 (KEGG: rho $=0.52, p=6 \times 10^{-15}$, Reactome: $\left.r h o=0.45, p=0\right)$ (Figure 7). For example, concordant Reactome pathways included Nuclear receptor transcription pathway, TNF signaling, and VEGF ligand-receptor interactions, while non-concordant Reactome pathways included Apoptotic execution phase and TRAIL signaling. The full list of regulated pathways in TNBS and IBD is accessible through supplementary Table S3.
In situ hybridization (ISH) of target genes in TNBS-colitis

Markers of mucosal inflammation and selected microarray targets were analyzed using ISH. These included inflammatory cytokines (IL- $1 \alpha$ and IL-1 $\beta$ ) and TLRs (TLR2 and TLR4), as well as the computationally identified genes PPAR $\gamma$ and PRNP.

An overall increase in gene expression of IL- $1 \alpha$ and IL- $1 \beta$ was evident in submucosal inflammatory infiltrates at T3-T12. However, changes in expression varied with the degree of inflammation in individual animals. Colitis induction resulted in increased expression of TLR2 and TLR4 in epithelial cells (Figure 8A, B, C and D). PRNP expression was increased both in submucosal inflammatory cells and to some degree also in 
Table 1. P-values and FCs for the target genes at every time point.

\begin{tabular}{|c|c|c|c|c|c|c|}
\hline \multirow[t]{2}{*}{ Gene } & \multicolumn{2}{|l|}{ T3 } & \multicolumn{2}{|l|}{ T7 } & \multicolumn{2}{|l|}{ T12 } \\
\hline & FC & P-value & FC & P-value & FC & P-value \\
\hline $\mid \mathrm{IL}-1 \alpha$ & 8.63 & 0.008 & 3.38 & 0.091 & 1.58 & 0.209 \\
\hline IL-1 $\beta$ & 6.16 & 0.063 & 4.74 & 0.047 & 1.94 & 0.071 \\
\hline TLR2 & 5.03 & 0.005 & 3.46 & 0.029 & 1.75 & 0.027 \\
\hline TLR4 & 2.09 & $<0.001$ & 1.36 & 0.001 & 1.67 & 0.005 \\
\hline PRNP & 2.13 & 0.005 & 2.11 & 0.005 & 1.89 & 0.016 \\
\hline PPAR $\gamma$ & -4.14 & $<0.001$ & -3.05 & $<0.001$ & -4.63 & $<0.001$ \\
\hline
\end{tabular}

epithelial cells (Figure 8F), while a substantial down-regulation of PPAR $\gamma$ was evident in the epithelium after induction of colitis (Figure $8 \mathrm{H}$ ). The in situ results correlated well with the differential expression noted in the microarray, IL- $1 \alpha(\mathrm{FC}$ at $\mathrm{T} 3=8.6$, $p=0.008$ ), IL-1 $\beta$ (FG at T7 $=4.7, p=0.047)$, TLR2 (FG at $\mathrm{T} 3=5.03, p=0.005)$, TLR4 $(\mathrm{FG}$ at T3 $=2.09, p<0.001), \operatorname{PPAR} \gamma$ $(\mathrm{FG}$ at $\mathrm{T} 12=-4.6, p<0.001)$, and $\operatorname{PRNP}(\mathrm{FG}$ at T3=2.1, $p=0.005)$. $\mathrm{P}$-values and FCs for the target genes at every time point are provided in Table 1 .

\section{PCR validation of selected genes}

PCR was performed for the following genes: SPINK4, ADA, and FABP1. Mean FGs for SPINK4 were 93.26 for T3 vs. T0, 4.02 for $\mathrm{T} 7$ vs. T0 and 1.76 for T12 vs. T0. The corresponding FGs for ADA were 11.93, 16.87 and 13.20 and for FABP1 $-199.96,-105.60$ and -170.62 which were in accordance with the microarray results (Figure 9).

\section{Discussion}

TNBS-colitis is widely used as a model for IBD. However, its resemblance to human disease has not been thoroughly explored. TNBS-colitis in rats was originally described as a model for induction of long lasting inflammation and ulceration of the rat colon [12], and the reproducibility was emphasized. The reproducibility and duration/chronicity of inflammation has, however, been subject to debate $[14,41]$. In the current study, we standardized the protocol for induction of moderate TNBS-colitis in Sprague Dawley rats and evaluated temporal changes in gene expression profiles and biological pathways after the induction of colitis. Importantly, we quantitatively assessed concordance of the TNBS-colitis and IBD transcriptomes.

Doses and concentrations of TNBS used in previous studies differ markedly and no standardized protocol has been generally developed [14,17-20]. We therefore aimed to optimize the method to achieve a reproducible moderate colitis. High concentrations of TNBS $(60 \mathrm{mg} / \mathrm{ml})$, administered in small volumes $(0.29$ and $0.38 \mathrm{ml})$ induced a localized severe inflammation resulting in deep colonic ulcerations, coprostasis, stenoses and ileus. Milder inflammation and more wide spread inflammation was achieved with lower TNBS concentrations in a larger total volume. A TNBS concentration of $30 \mathrm{mg} / \mathrm{ml}$ in a total volume of $0.6 \mathrm{ml}$ resulted in a moderate inflammation involving most of the left colon. However, despite the use of a standardized protocol, a slight inter-individual dissimilarity in the extension and degree of inflammation was seen, reflected by variation in MEICS-score and expression of the pro-inflammatory cytokines IL- $1 \alpha$ and IL- $1 \beta$.
Natural inter-individual variation and factors like anal leakage of TNBS and incomplete bowel emptying prior to the instillation are likely contributors to these observations. To minimize these effects, fecal pellets in the rectum should be eliminated prior to TNBSinstillation.

TNBS induces a hapten-mediated toxic inflammation, and consequently has unavoidable differences compared to IBD [42]. In addition to chemical inflammation, the intestinal microbiota is important in the development of TNBS-colitis [43]. Granulomas have been described in approximately $50 \%$ of rats with TNBScolitis [12]. However, no granulomas were seen in the current study. This may reflect disparities in the microbiota seen in different animal housing facilities.

Endoscopic monitoring of TNBS-colitis with visual assessment has been described. However, in those studies no biopsies were obtained [44,45]. In another study, transcriptomic analysis of TNBS-colitis was performed using whole colon specimens from animals sacrificed at different time points [21]. Consequently, temporal changes in gene expression in individual rats during colitis development has not been investigated. Furthermore, a comparison with a human IBD transcriptome has not been conducted. Our approach thus allows investigators to follow the development of colitis in individual animals visually, and collect biopsies for histologic evaluation and genetic analyses. Endoscopy three days after TNBS instillation allowed for a baseline evaluation of the inflammation. Rats with comparable colitis could therefore be identified prior to study inclusion. A similar approach has been described using MRI to grade the inflammation [14]. In addition, as the animals serve as their own controls it reduces the overall study number.

Computational analysis of longitudinal gene expression profiles in the TNBS-colitis model in this study revealed alterations such as a down-regulation of metabolism and up-regulation of tissue remodeling genes. This suggests that mucosal cells may be deprived of adequate energy sources as well as exposed to profibrotic signaling cascades during the inflammatory response. Similar changes have been reported in IBD patients [46,47] and models of experimental colitis [21]. Additionally, we noted downregulation of processes including DNA replication and cell cycle, which involved genes such as caspase 1 and 3 (Caspl/3). Caspl is an enzyme that proteolytically cleaves precursor forms of the inflammatory cytokines IL-1 $\beta$ and IL-18, while Casp3 proteolytically inactivates IL-33, which is a member of the IL-1 superfamily [48]. Interestingly, $\mathrm{Casp}^{-/-}$mice are more susceptible to inflammation-induced tumorigenesis in the colon [49], while IL33 was recently found to be increased in ulcerative colitis [50,51]. Additionally, previous experimental models have demonstrated that Casp $^{-\gamma}$ mice are also more susceptible to infections [52] and are more sensitive to DSS-colitis [53]. Taken together, the temporal analysis of TNBS-colitis gene expression profiles revealed biologically relevant changes in key IBD pathways, suggesting that the transcriptome dataset in this study is a useful resource for further biological discovery in this animal model.

Contributions of model organisms to our understanding of generalizable fundamental processes are irrefutable. However, little work has been done to quantitatively assess the concordance between TNBS-colitis and IBD transcriptomes. In our analyses, we noted a divergence between rat and human transcriptomes at the level of single gene loci with only 233-765 (3.8-12.5\%) concordant gene loci out of 6142 analyzed. However, several key IBD genes were similarly regulated in the TNBS model and IBD. Genes involved in fibrogenesis and stricture formation [54,55], including collagen type I alpha (COL1A1), matrix metallopeptidase 3 (MMP3) and TIMP metallopeptidase inhibitor 1 and 2 


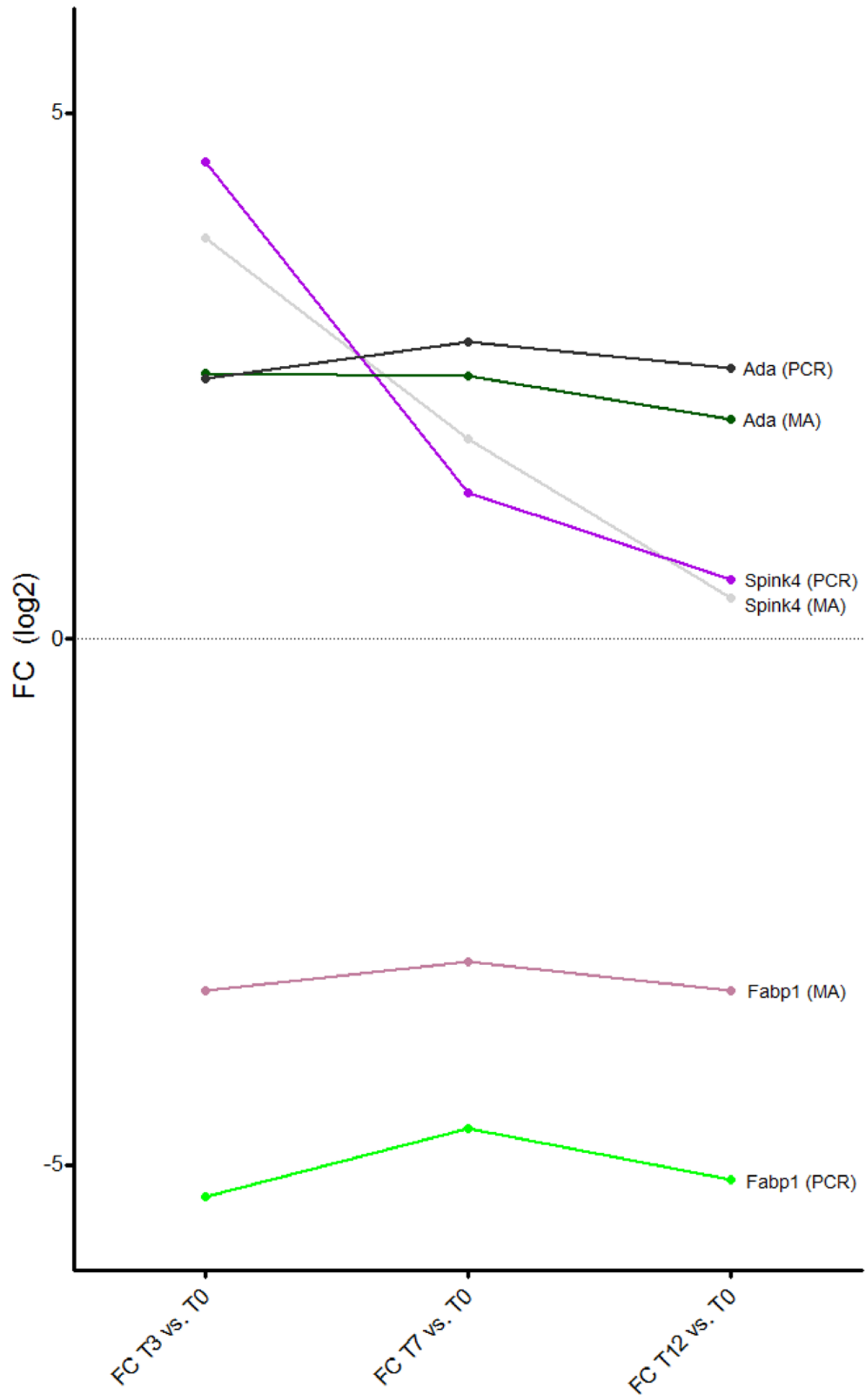

Figure 9. Graph displaying confirmatory PCR. Graph displaying FC for T3 vs. TO, T7 vs. T0 and T12 vs. TO for SPINK4, ADA and FABP1 for both microarray (MA) and confirmatory PCR. FC is log2 transformed for illustrative purposes. All $p$-values are highly significant. doi:10.1371/journal.pone.0054543.g009

(TIMP1 and TIMP2) are examples thereof. These findings are consistent with other comparative assessments of human disease and animal models [56,57]. Our group has shown that the REG family proteins and CXCL10 are up-regulated in IBD [58,59].
The REG proteins probably play a role in induction of cellular proliferation and induction of apoptosis, thus being of importance for tissue repair and growth. CXCL10 seems to be released from epithelial cells acting as a ligand on CXCLR3+ T-lymphocytes, 
contributing to the inflammatory response in IBD. In contrast to these results, both REGIV and CXCL10 were down-regulated in the TNBS-model. It is possible that the duration of the TNBSstudy was too short to detect a delayed activation of REGIV, however the discrepancy might also reflect the difference between IBD and TNBS-colitis. The discrepancy in regulation of CXCL10 also demonstrates the dissimilarity between human disease and TNBS-colitis. Other chemokines like CXCL1 and CXCL2, have previously been found up-regulated in TNBS-colitis [21] and were up-regulated in our data. We also found CXCL16 to be 1.5 fold elevated at T3. CXCL16 has a role in phagocytosis, mucosal defense and Th1-mediated inflammation, and has been implicated in the pathogenesis of IBD [60-62].

Despite differences at the level of single gene loci, considerably higher homology was noted between TNBS-colitis and IBD at the level of biological pathways. For KEGG-pathways 114-134 (58.5$68.7 \%$ ) of 195 pathways, while for the Reactome 515-631 (56.3$69.0 \%$ ) of 915 pathways were concordant. This result was expected, since previous work demonstrates that pathway level analysis is able to uncover subtle biological variability, which may not be captured by gene expression alone [63]. Concordant pathways included Cell junction organization, Interleukin-1 processing, and Dysregulation of fatty acid metabolism. These pathways represent key elements of IBD pathogenesis. For example, the ability to organize tight junctions, adherent junctions and desmosomes are important protective mechanisms that prevent microorganism invasion, mucosal damage and inflammation [64]. Similarly, aberrant regulation of $\mathrm{IL}-1 \alpha$ and $\mathrm{IL}-1 \beta$ is a contributing mechanism in persistent inflammation in IBD [65,66], while alterations in the expression of genes involved in fatty acid metabolism may contribute to the pathophysiology of ulcerative colitis [46].

Among non-concordant pathways, we identified TRAIL signaling as being different between the rat model and IBD. This signaling pathway mediates apoptosis and might be of importance for T-cell death as a therapeutic target in IBD [67].

Overall, these concordance analyses suggests that TNBS-colitis is an appropriate IBD model for the study of specific biological processes such as Cell junction organization and Fatty acid metabolism, while caution needs to be exercised when analysis is based on a single gene locus.

Other chemically induced colitis models exist. Colitis induced through addition of the polysaccharide dextran sodium sulfate (DSS) in the drinking water or rectal instillation of oxazolone are examples thereof [68]. DSS and TNBS have clinical similarities including bloody diarrhea and weight loss. However, inflammation in DDS seems to be caused by hyperosmotic damage and is confined to the mucosa and lamina propria, in contrast to the TNBS-model where inflammation is hapten-mediated and transmural [69]. Additionally germ free mice develop a lethal colitis when exposed to DSS [70], while a sterile colon seems to be protective against TNBS-colitis [43]. A comparison of genetic expression between DSS, TNBS and CD45RB transfer colitis mice showed that DSS and TNBS had 6 and 18 concordantly upand down-regulated genes [71]. Another study found 152 and 22 concordantly up- and down-regulated genes between mice with DSS-colitis and UC from a total of 1609 differentially expressed genes [72]. In an analysis of cytokine patterns, closer resemblance was indicated between DSS-colitis and UG, while TNBS-colitis seemed closer to CD [73]. Oxazolone is another example of a rectally administered substance that causes a hapten-mediated colitis in the distal part of the colon with clinically similar symptoms as TNBS-colitis $[68,74]$. Oxazolon-induced colitis is mainly driven by Th2 cytokines, while TNBS-colitis is Th1- and Th17-mediated [11,73,74].

Several gene knockout models in mice have been used to study possible pathogenetic mechanisms in IBD. Deletion of the regulatory sequence consisting of adenosine-uracil multimers (AU-rich elements [ARE]) in the $3^{\prime}$-untranslated region of cytokine encoding transcripts in mice $\left(\mathrm{TNF}_{-}{ }^{\Delta \mathrm{ARE} /+}\right.$ ), results in mice with increased transcription of TNF- $\alpha$; after lipopolysaccharide (LPS)-stimulation these mice develop terminal ileitis and inflammatory arthritis [68,75]. IL-10 knockout mice develop inflammation, mainly localized to the colon [76]. The IL-10 knockout model has highlighted the importance of IL-10 as an anti-inflammatory cytokine. IL-10 is increased in the serum of recovering IBD-patients [77]. IL-10 was not significantly regulated in our TNBS-model which might suggest that IL-10 does not participate in the healing of TNBS colitis.

We sought to validate key changes in the TNBS-colitis transcriptome using ISH. Genes with known roles and of potential importance in IBD were evaluated, namely IL- $1 \alpha$, IL-1 $\beta$, TLR2, TLR4, PPAR $\gamma$ and PRNP. Gene expression profiling revealed that IL- $1 \alpha$ and IL- $1 \beta$ were significantly up-regulated at T3 and T7, compared to T0, while TLR2, TLR4 and PRNP were significantly up-regulated at every time point (T3, T7 and T12) compared to T0. PPAR $\gamma$ was significantly down-regulated at every time point.

ISH confirmed that both IL- $1 \alpha$ and IL- $1 \beta$ were weakly expressed in colonic epithelial cells while high expression was found in leukocytes and inflammatory infiltrates. Mediation of inflammation by IL- $1 \alpha$ and IL- $1 \beta$ is balanced or counteracted via the IL-1 receptor antagonist (IL-1ra), which was significantly upregulated at every time point. It has previously been shown in experimental colitis that neutralization of IL-1ra leads to more severe inflammation [78]. In concordance with the TNBS-colitis model, both IL- $1 \alpha$ and IL- $1 \beta$ are elevated in IBD. An imbalance between these IL-1s and IL-1ra might contribute to the pathogenesis in IBD $[65,79]$.

The increased TLR2 and TLR4 expression seen in the transcriptome analysis was confirmed by ISH with dense staining in epithelial cells at the luminal surface and in the crypt epithelium. Hitherto, 10 TLRs have been described in humans [6]. TLR1, TLR2, TLR4, TLR5, TLR6, and TLR9 all recognize bacterial products or bacterial components [80]. While TLR2 and TLR4 were up-regulated, TLR5 was significantly down-regulated in our TNBS-colitis model. Intestinal homeostasis between tolerance to intestinal microflora and activation of an inflammatory response appears to be dependent on the type of TLR involved and whether basolateral or apical TLRs are activated [81]. Similar to the TNBS-colitis model, activation of both TLR2 and TLR4 is seen in IBD $[5,82,83]$. Probiotic treatment also activates TLR2, TLR4 and TLR9 and modulates cytokine production and secretion [84]. Interestingly, IL-10 and TLR4 double knockout mice have an accelerated colitis development compared to IL-10 and TLR9 double knockout and IL-10 single knockout which do not develop colitis [85]. TLR2 and TLR4 upregulation in epithelial cells in this TNBS-colitis model as well as the cytokine up-regulation indicate bacterial activation of mucosal defense and inflammation [5]. Clearly, the mechanisms of TLRresponse are complicated. The mechanisms for the balance of an adequate immune response and adaption of the innate immune system, on one hand, and an inadequate immune response, on the other hand, can partly be explained by tolerance development and polarization differences in TLR-receptor distribution [86,87].

PRNP $\left(\operatorname{PrP}^{\mathrm{c}}\right)$ mRNA was significantly up-regulated in TNBScolitis. This was verified by ISH which showed expression in 
submucosal immune cells and some expression in epithelial cells in animals not yet exposed to TNBS, but expression was more pronounced after colitis induction both in the submucosal immune cells and within the epithelium. $\operatorname{PrP}^{\mathrm{c}}$ is expressed in several tissues, including neural tissue, gut-associated lymphoid tissue, enteroendocrine cells and enterocytes [28,88]. Its function is not well known. Expression of $\operatorname{PrP}^{\mathrm{c}}$ in the host is thought to be necessary for the propagation and transmission of prion infection [28]. In addition, both pro- and anti-inflammatory roles have been suggested. Reduced inflammatory infiltration has been seen in $\operatorname{PrP}^{\mathrm{c}}$-deficient mice upon stimulation with TLR2 and TLR4 ligands [26]. In contrast, $\operatorname{Pr}^{c}$ over-expressing mice are resistant to colitis induction with DSS while $\operatorname{PrP}^{\mathrm{c}}$ deficient mice had significantly higher levels of inflammatory cytokines compared to DSS-treated wild type mice [29]. Increased intestinal barrier permeability has been demonstrated in $\mathrm{PrP}^{\mathrm{c}}$-deficient mice, further supporting a protecting role for $\operatorname{PrP}^{\mathrm{c}}$ [89] in colitis and IBD.

PPAR $\gamma$ is one of three identified isoforms of peroxisome proliferator-activated receptors (PPARs) and is expressed in several tissues; expression is high in the colonic epithelial cells [90,91]. It is thought to have an important role in modulation of inflammation. PPAR $\gamma$ suppresses inflammatory cytokines like TNF $\alpha$, interleukin6 (IL-6) and IL-1 $\beta$ [24] and maintains defensin production [25]. Gene expression analysis revealed down-regulation of PPAR $\gamma$ after colitis induction. In endoscopic biopsies evaluated by ISH, a high basal expression of PPAR $\gamma$ in non-inflamed colonic epithelium, while a considerable down-regulation in inflamed colon epithelium was identified. This was accompanied by downregulation of FABP1. FABP1 transcription, in the microarray was confirmed by PCR. The intracellular level of FABP1 positively regulates $\operatorname{PPAR} \gamma$ and the two proteins also have a direct proteinprotein interaction [92]. Regulation of FABPs is seen in IBD [46], PPAR $\gamma$ is down-regulated in UC [93] and gene polymorphisms of PPAR $\gamma$ have been implicated in the pathogenesis of CD [42,94]. PPAR $\gamma$-agonists have been shown to ameliorate TNBS-induced colitis $[95,96]$ and the PPAR $\gamma$ ligand rosiglitazone has shown efficacy in mild to moderately active IBD [97]. PPAR $\gamma$ might also inhibit tumor growth in colorectal cancer [98]. Alternatively, FABP1 has been suggested as a biomarker of CD because a 10fold up-regulation was found in one study [99]. Our findings, in contrast, are consistent with loss of PPAR $\gamma$-mediated antiinflammatory effects. This supports a potentially important function for PPAR $\gamma$ in the regulation of colonic inflammation and indicates that FABPs could also be a possible target for therapy.

Among the 20 genes with highest $\mathrm{FC}$ at all time points were SPINK4; lipopolysaccharide binding protein (LBP), ADA and RETNLB. PCR validation was performed for SPINK4 and ADA. SPINK4 has recently been identified as a risk locus for UC [100] and increased expression is seen in untreated celiac disease [101]. LBP transfers LPS to the LPS-signaling receptor complex (which also contains TLR4), promotes innate immunity against gram negative bacteria, and may serve as a marker of disease activity in CD [102]. ADA deactivates adenosine and thus diminishes the

\section{References}

1. Danese S, Fiocchi C (2011) Ulcerative colitis. N Engl J Med 365: 1713-1725.

2. Hammer HF (2011) Gut microbiota and inflammatory bowel disease. Dig Dis 29: 550-553.

3. McGuckin MA, Eri R, Simms LA, Florin TH, Radford-Smith G (2009) Intestinal barrier dysfunction in inflammatory bowel diseases. Inflamm Bowel Dis 15: 100-113. potentially protective effects of adenosine in mucosal inflammation and hypoxia. A beneficial effect after inhibition of ADA has been demonstrated in experimental colitis $[103,104]$. RETNLB had a FC of 470 and 253 at T7 and T12, respectively. RETNLBdeficiency in mice increases intestinal permeability and RETNLB seems important to maintain intestinal homeostasis [105].

In conclusion, endoscopy with biopsies in TNBS-colitis models is useful to visually follow temporal changes of inflammation and obtain tissue for histologic and gene expression measurements. TLR and interleukin activation, PPAR $\gamma$-inhibition and regulation of PRNP $\left(\operatorname{PrP}^{\mathrm{c}}\right)$, occurs in both TNBS-colitis and IBD. TNBScolitis is an appropriate IBD-model to study specific biological processes like TNF signaling, Cell junction organization, and Interleukin-1 processing. We conclude that the TNBS-model may be suitable for studying agents targeting these pathways and provide translational information for clinical studies.

\section{Supporting Information}

Figure S1 Concordance analysis between TNBS-colitis and IBD transcriptomes at the level of single gene loci. See Figure 6.

(TIF)

Figure S2 Concordance analysis between TNBS-colitis and IBD transcriptomes at the level of biological pathways. See Figure 7.

(TIF)

Table S1 Genes identified with Ensemble IDs, Gene Symbols and Gene Names and their respective cluster assignments (1-13) with involved GO-BPs and KEGG Pathways.

(XLS)

Table S2 Concordant genes identified with Ensemble IDs, Gene Symbols and Gene Names with corresponding FC, $p$-value and False Discovery Rate (FDR) for TNBS, $\mathrm{CD}$ and $\mathrm{UC}$, respectively.

(XLS)

Table S3 Homologous pathways (KEGG, Sheet 1) and (Reactome, Sheet 2) in TNBS-colitis compared to GD and UC for different time points of TNBS-colitis (T3, T7 and T12).

(XLS)

\section{Acknowledgments}

We want to thank Bjørn Munkvold for laboratory assistance and the staff at the animal facility for their helpfulness and good animal care.

\section{Author Contributions}

Conceived and designed the experiments: BG ØB MWF RM. Performed the experiments: ØB MWF BG AvBG RTMZ. Analyzed the data: ØB BG ID AvBG AF AS ISN MK. Contributed reagents/materials/analysis tools: ØB BG ID AvBG AF AS RM. Wrote the paper: ØB MWF ID AvBG AS ISN MK BG.

4. Kleessen B, Kroesen AJ, Buhr HJ, Blaut M (2002) Mucosal and invading bacteria in patients with inflammatory bowel disease compared with controls. Scand J Gastroenterol 37: 1034-1041.

5. Cario E, Podolsky DK (2000) Differential alteration in intestinal epithelial cell expression of toll-like receptor 3 (TLR3) and TLR4 in inflammatory bowel disease. Infect Immun 68: 7010-7017.

6. Cario E (2010) Toll-like receptors in inflammatory bowel diseases: a decade later. Inflamm Bowel Dis 16: 1583-1597. 
7. De Jager PL, Franchimont D, Waliszewska A, Bitton A, Cohen A, et al. (2007) The role of the Toll receptor pathway in susceptibility to inflammatory bowel diseases. Genes Immun 8: 387-397.

8. Strober W, Fuss I, Mannon P (2007) The fundamental basis of inflammatory bowel disease. J Clin Invest 117: 514-521.

9. MacDonald TT, Biancheri P, Sarra M, Monteleone G (2012) What's the next best cytokine target in IBD? Inflamm Bowel Dis 18: 2180-2189.

10. Jurjus AR, Khoury NN, Reimund JM (2004) Animal models of inflammatory bowel disease. J Pharmacol Toxicol Methods 50: 81-92.

11. Neurath M, Fuss I, Strober W (2000) TNBS-colitis. Int Rev Immunol 19: 5162.

12. Morris GP, Beck PL, Herridge MS, Depew WT, Szewczuk MR, et al. (1989) Hapten-induced model of chronic inflammation and ulceration in the rat colon. Gastroenterology 96: 795-803.

13. Wallace JL, Le T, Carter L, Appleyard CB, Beck PL (1995) Hapten-induced chronic colitis in the rat: alternatives to trinitrobenzene sulfonic acid. J Pharmacol Toxicol Methods 33: 237-239.

14. Pohlmann A, Tilling LC, Robinson A, Woolmer O, McCleary S, et al. (2009) Progression and variability of TNBS colitis-associated inflammation in rats assessed by contrast-enhanced and T2-weighted MRI. Inflamm Bowel Dis 15: 534-545.

15. Kim I, Kong H, Lee Y, Hong S, Han J, et al. (2009) Dexamethasone 21-sulfate improves the therapeutic properties of dexamethasone against experimental rat colitis by specifically delivering the steroid to the large intestine. Pharm Res 26: 415-421.

16. Shen G, de Hertogh G, Bullens DM, Van Assche G, Geboes K, et al. (2007) Remission-inducing effect of anti-TNF monoclonal antibody in TNBS colitis: mechanisms beyond neutralization? Inflamm Bowel Dis 13: 308-316.

17. Chen Y, Liu WL, Zhou TH, CaiJT, Du Q et al. (2009) Therapeutic effects of rectal administration of muscovite on experimental colitis in rats. J Gastroenterol Hepatol 24: 912-919.

18. Akcan A, Kucuk C, Sozuer E, Esel D, Akyildiz H, et al. (2008) Melatonin reduces bacterial translocation and apoptosis in trinitrobenzene sulphonic acidinduced colitis of rats. World J Gastroenterol 14: 918-924.

19. Pan XQ Gonzalez JA, Chang S, Chacko S, Wein AJ, et al. (2010) Experimental colitis triggers the release of substance $\mathrm{P}$ and calcitonin generelated peptide in the urinary bladder via TRPV1 signaling pathways. Exp Neurol 225: 262-273.

20. Ohta N, Tsujikawa T, Nakamura T, A I (2003) Different-sized triglycerides chains do not influence colitis induced by trinitrobenzene sulfonic acid in rats. Nutr Res 23: 279-286.

21. Martinez-Augustin O, Merlos M, Zarzuelo A, Suarez MD, de Medina FS (2008) Disturbances in metabolic, transport and structural genes in experimental colonic inflammation in the rat: a longitudinal genomic analysis. BMC Genomics 9: 490

22. Abreu MT (2010) Toll-like receptor signalling in the intestinal epithelium: how bacterial recognition shapes intestinal function. Nat Rev Immunol 10: 131 144.

23. Willson TM, Lambert MH, Kliewer SA (2001) Peroxisome proliferatoractivated receptor gamma and metabolic disease. Annu Rev Biochem 70: 341367.

24. Jiang C, Ting AT, Seed B (1998) PPAR-gamma agonists inhibit production of monocyte inflammatory cytokines. Nature 391: 82-86.

25. Peyrin-Biroulet L, Beisner J, Wang G, Nuding S, Oommen ST, et al. (2010) Peroxisome proliferator-activated receptor gamma activation is required for maintenance of innate antimicrobial immunity in the colon. Proc Natl Acad Sci U S A 107: 8772-8777.

26. Linden R, Martins VR, Prado MA, Cammarota M, Izquierdo I, et al. (2008) Physiology of the prion protein. Physiol Rev 88: 673-728.

27. Marcos Z, Pffeifer K, Bodegas ME, Sesma MP, Guembe L (2004) Cellular prion protein is expressed in a subset of neuroendocrine cells of the rat gastrointestinal tract. J Histochem Cytochem 52: 1357-1365.

28. Ford MJ, Burton LJ, Morris RJ, Hall SM (2002) Selective expression of prion protein in peripheral tissues of the adult mouse. Neuroscience 113: 177-192.

29. Martin GR, Keenan CM, Sharkey KA, Jirik FR (2011) Endogenous prion protein attenuates experimentally induced colitis. Am J Pathol 179: 2290-2301.

30. Becker C, Fantini MC, Wirtz S, Nikolaev A, Kiesslich R, et al. (2005) In vivo imaging of colitis and colon cancer development in mice using high resolution chromoendoscopy. Gut 54: 950-954.

31. Du P, Kibbe WA, Lin SM (2008) lumi: a pipeline for processing Illumina microarray. Bioinformatics 24: 1547-1548.

32. Aryee MJ, Gutierrez-Pabello JA, Kramnik I, Maiti T, Quackenbush J (2009) An improved empirical bayes approach to estimating differential gene expression in microarray time-course data: BETR (Bayesian Estimation of Temporal Regulation). BMC Bioinformatics 10: 409

33. Birney E, Andrews TD, Bevan P, Caccamo M, Chen Y, et al. (2004) An overview of Ensembl. Genome Res 14: 925-928.

34. Frey BJ, Dueck D (2007) Clustering by passing messages between data points. Science 315: 972-976.

35. Ashburner M, Ball CA, Blake JA, Botstein D, Butler H, et al. (2000) Gene ontology: tool for the unification of biology. The Gene Ontology Consortium. Nature genetics 25: 25-29.
36. Shi Z, Derow CK, Zhang B (2010) Co-expression module analysis reveals biological processes, genomic gain, and regulatory mechanisms associated with breast cancer progression. BMC Syst Biol 4: 74

37. Drozdov I, Ouzounis CA, Shah AM, Tsoka S (2011) Functional Genomics Assistant (FUGA): a toolbox for the analysis of complex biological networks. $\mathrm{BMC}$ research notes 4: 462.

38. Kanehisa M, Goto S, Sato Y, Furumichi M, Tanabe M (2012) KEGG for integration and interpretation of large-scale molecular data sets. Nucleic acids research 40: D109-114.

39. Vastrik I, D'Eustachio P, Schmidt E, Gopinath G, Croft D, et al. (2007) Reactome: a knowledge base of biologic pathways and processes. Genome biology 8: R39.

40. Lee E, Chuang HY, Kim JW, Ideker T, Lee D (2008) Inferring pathway activity toward precise disease classification. PLoS computational biology 4: e1000217.

41. Knollmann FD, Dietrich T, Bleckmann T, Bock J, Maurer J, et al. (2002) Magnetic resonance imaging of inflammatory bowel disease: evaluation in a rabbit model. J Magn Reson Imaging 15: 165-173.

42. Hugot JP (2005) PPAR and Crohn's disease: another piece of the puzzle? Gastroenterology 128: 500-503.

43. Guarner F, Malagelada JR (2003) Role of bacteria in experimental colitis. Best Pract Res Clin Gastroenterol 17: 793-804.

44. Shibata Y, Taruishi M, Ashida T (1993) Experimental ileitis in dogs and colitis in rats with trinitrobenzene sulfonic acid - colonoscopic and histopathologic studies. Gastroenterol Jpn 28: 518-527.

45. Vermeulen W, De Man JG, Nullens S, Pelckmans PA, De Winter BY, et al. (2011) The use of colonoscopy to follow the inflammatory time course of TNBS colitis in rats. Acta Gastroenterol Belg 74: 304-311.

46. Heimerl S, Moehle C, Zahn A, Boettcher A, Stremmel W, et al. (2006) Alterations in intestinal fatty acid metabolism in inflammatory bowel disease. Biochim Biophys Acta 1762: 341-350.

47. Rieder F, Fiocchi C (2008) Intestinal fibrosis in inflammatory bowel disease: progress in basic and clinical science. Current opinion in gastroenterology 24: $462-468$

48. Luthi AU, Cullen SP, McNeela EA, Duriez PJ, Afonina IS, et al. (2009) Suppression of interleukin-33 bioactivity through proteolysis by apoptotic caspases. Immunity 31: 84-98.

49. Hu B, Elinav E, Huber S, Booth CJ, Strowig T, et al. (2010) Inflammationinduced tumorigenesis in the colon is regulated by caspase-1 and NLRC4. Proc Natl Acad Sci U S A 107: 21635-21640.

50. Kobori A, Yagi Y, Imaeda H, Ban H, Bamba S, et al. (2010) Interleukin-33 expression is specifically enhanced in inflamed mucosa of ulcerative colitis. Journal of gastroenterology 45: 999-1007.

51. Seidelin JB, Bjerrum JT, Coskun M, Widjaya B, Vainer B, et al. (2010) IL-33 is upregulated in colonocytes of ulcerative colitis. Immunol Lett 128: 80-85.

52. Brinkman BM, Hildebrand F, Kubica M, Goosens D, Del Favero J, et al. (2011) Caspase deficiency alters the murine gut microbiome. Cell death \& disease 2: e220.

53. Dupaul-Chicoine J, Yeretssian G, Doiron K, Bergstrom KS, McIntire CR, et al. (2010) Control of intestinal homeostasis, colitis, and colitis-associated colorectal cancer by the inflammatory caspases. Immunity 32: 367-378.

54. Lawrance IC, Fiocchi C, Chakravarti S (2001) Ulcerative colitis and Crohn's disease: distinctive gene expression profiles and novel susceptibility candidate genes. Hum Mol Genet 10: 445-456.

55. Rieder F, Brenmoehl J, Leeb S, Scholmerich J, Rogler G (2007) Wound healing and fibrosis in intestinal disease. Gut 56: 130-139.

56. Miller JA, Horvath S, Geschwind DH (2010) Divergence of human and mouse brain transcriptome highlights Alzheimer disease pathways. Proc Natl Acad Sci U S A 107: 12698-12703.

57. Gollamudi S, Johri A, Calingasan NY, Yang L, Elemento O, et al. (2012) Concordant signaling pathways produced by pesticide exposure in mice correspond to pathways identified in human Parkinson's disease. PLoS One 7: e36191.

58. Granlund AB, Beisvag V, Torp SH, Flatberg A, Kleveland PM, et al. (2011) Activation of REG family proteins in colitis. Scand J Gastroenterol 46: 13161323.

59. Ostvik AE, Vb Granlund A, Bugge M, Nilsen NJ, Torp SH, et al. (2012) Enhanced expression of CXCL10 in inflammatory bowel disease: Potential role of mucosal toll-like receptor 3 stimulation. Inflamm Bowel Dis.

60. Lehrke M, Konrad A, Schachinger V, Tillack C, Seibold F, et al. (2008) CXCL16 is a surrogate marker of inflammatory bowel disease. Scand J Gastroenterol 43: 283-288.

61. Uza N, Nakase H, Yamamoto S, Yoshino T, Takeda Y, et al. (2011) SRPSOX/CXCL16 plays a critical role in the progression of colonic inflammation. Gut 60: 1494-1505.

62. Olszak T, An D, Zeissig S, Vera MP, Richter J, et al. (2012) Microbial exposure during early life has persistent effects on natural killer $\mathrm{T}$ cell function. Science 336: 489-493.

63. Mootha VK, Lindgren CM, Eriksson KF, Subramanian A, Sihag S, et al. (2003) PGC-1 alpha-responsive genes involved in oxidative phosphorylation are coordinately downregulated in human diabetes. Nature genetics 34: 267-273.

64. Gassler N, Rohr C, Schneider A, Kartenbeck J, Bach A, et al. (2001) Inflammatory bowel disease is associated with changes of enterocytic junctions. Am J Physiol Gastrointest Liver Physiol 281: G216-228. 
65. Casini-Raggi V, Kam L, Chong YJ, Fiocchi C, Pizarro TT, et al. (1995) Mucosal imbalance of IL-1 and IL-1 receptor antagonist in inflammatory bowel disease. A novel mechanism of chronic intestinal inflammation. J Immunol 154: 2434-2440.

66. Cominelli F, Pizarro TT (1996) Interleukin-1 and interleukin-1 receptor antagonist in inflammatory bowel disease. Aliment Pharmacol Ther 10 Suppl 2: 49-53; discussion 54

67. Mudter J, Neurath MF (2007) Apoptosis of $\mathrm{T}$ cells and the control of inflammatory bowel disease: therapeutic implications. Gut 56: 293-303.

68. Mizoguchi A (2012) Animal models of inflammatory bowel disease. Prog Mol Biol Transl Sci 105: 263-320.

69. Gaudio E, Taddei G, Vetuschi A, Sferra R, Frieri G, et al. (1999) Dextran sulfate sodium (DSS) colitis in rats: clinical, structural, and ultrastructural aspects. Dig Dis Sci 44: 1458-1475.

70. Kitajima S, Morimoto M, Sagara E, Shimizu C, Ikeda Y (2001) Dextran sodium sulfate-induced colitis in germ-free IQI/Jic mice. Exp Anim 50: 387395.

71. te Velde AA, de Kort F, Sterrenburg E, Pronk I, ten Kate FJ, et al. (2007) Comparative analysis of colonic gene expression of three experimental colitis models mimicking inflammatory bowel disease. Inflamm Bowel Dis 13: 325330.

72. Fang K, Bruce M, Pattillo CB, Zhang S, Stone R, 2nd, et al. (2011) Temporal genomewide expression profiling of DSS colitis reveals novel inflammatory and angiogenesis genes similar to ulcerative colitis. Physiol Genomics 43: 43-56.

73. Alex P, Zachos NC, Nguyen T, Gonzales L, Chen TE, et al. (2009) Distinct cytokine patterns identified from multiplex profiles of murine DSS and TNBSinduced colitis. Inflamm Bowel Dis 15: 341-352.

74. Wirtz S, Neufert C, Weigmann B, Neurath MF (2007) Chemically induced mouse models of intestinal inflammation. Nat Protoc 2: 541-546.

75. Kontoyiannis D, Pasparakis M, Pizarro TT, Cominelli F, Kollias G (1999) Impaired on/off regulation of TNF biosynthesis in mice lacking TNF AU-rich elements: implications for joint and gut-associated immunopathologies. Immunity 10: 387-398.

76. Rennick DM, Fort MM, Davidson NJ (1997) Studies with IL-10 - / - mice: an overview. J Leukoc Biol 61: 389-396.

77. Mitsuyama K, Tomiyasu N, Takaki K, Masuda J, Yamasaki H, et al. (2006) Interleukin-10 in the pathophysiology of inflammatory bowel disease: increased serum concentrations during the recovery phase. Mediators Inflamm 2006: 26875.

78. Ferretti M, Casini-Raggi V, Pizarro TT, Eisenberg SP, Nast CC, et al. (1994) Neutralization of endogenous IL-1 receptor antagonist exacerbates and prolongs inflammation in rabbit immune colitis. J Clin Invest 94: 449-453.

79. Pastorelli L, De Salvo C, Cominelli MA, Vecchi M, Pizarro TT (2011) Novel cytokine signaling pathways in inflammatory bowel disease: insight into the dichotomous functions of IL-33 during chronic intestinal inflammation. Therap Adv Gastroenterol 4: 311-323.

80. Doyle SL, O'Neill LA (2006) Toll-like receptors: from the discovery of NFkappaB to new insights into transcriptional regulations in innate immunity. Biochem Pharmacol 72: 1102-1113.

81. Lee J, Rachmilewitz D, Raz E (2006) Homeostatic effects of TLR9 signaling in experimental colitis. Ann N Y Acad Sci 1072: 351-355.

82. Sturm A, Dignass AU (2008) Epithelial restitution and wound healing in inflammatory bowel disease. World J Gastroenterol 14: 348-353.

83. Frolova L, Drastich P, Rossmann P, Klimesova K, Tlaskalova-Hogenova H (2008) Expression of Toll-like receptor 2 (TLR2), TLR4, and CD14 in biopsy samples of patients with inflammatory bowel diseases: upregulated expression of TLR2 in terminal ileum of patients with ulcerative colitis. J Histochem Cytochem 56: 267-274.

84. Castillo NA, Perdigon G, de Moreno de Leblanc A (2011) Oral administration of a probiotic Lactobacillus modulates cytokine production and TLR expression improving the immune response against Salmonella enterica serovar Typhimurium infection in mice. BMC Microbiol 11: 177.

85. Gonzalez-Navajas JM, Fine S, Law J, Datta SK, Nguyen KP, et al. (2010) TLR4 signaling in effector CD4+ $\mathrm{T}$ cells regulates TCR activation and experimental colitis in mice. J Clin Invest 120: 570-581.
86. Lee J, Gonzales-Navajas JM, Raz E (2008) The "polarizing-tolerizing" mechanism of intestinal epithelium: its relevance to colonic homeostasis. Semin Immunopathol 30: 3-9.

87. Otte JM, Cario E, Podolsky DK (2004) Mechanisms of cross hyporesponsiveness to Toll-like receptor bacterial ligands in intestinal epithelial cells. Gastroenterology 126: 1054-1070.

88. Morel E, Fouquet S, Chateau D, Yvernault L, Frobert Y, et al. (2004) The cellular prion protein PrPc is expressed in human enterocytes in cell-cell junctional domains. J Biol Chem 279: 1499-1505.

89. Petit CS, Barreau F, Besnier L, Gandille P, Riveau B, et al. (2012) Requirement of cellular prion protein for intestinal barrier function and mislocalization in patients with inflammatory bowel disease. Gastroenterology 143: 122-132 e115.

90. Fajas L, Auboeuf D, Raspe E, Schoonjans K, Lefebvre AM, et al. (1997) The organization, promoter analysis, and expression of the human PPARgamma gene. J Biol Chem 272: 18779-18789.

91. Su CG, Wen X, Bailey ST, Jiang W, Rangwala SM, et al. (1999) A novel therapy for colitis utilizing PPAR-gamma ligands to inhibit the epithelial inflammatory response. J Clin Invest 104: 383-389.

92. Wolfrum C, Borrmann CM, Borchers T, Spener F (2001) Fatty acids and hypolipidemic drugs regulate peroxisome proliferator-activated receptors alpha - and gamma-mediated gene expression via liver fatty acid binding protein: a signaling path to the nucleus. Proc Natl Acad Sci U S A 98: 2323-2328.

93. Dubuquoy L, Jansson EA, Deeb S, Rakotobe S, Karoui M, et al. (2003) Impaired expression of peroxisome proliferator-activated receptor gamma in ulcerative colitis. Gastroenterology 124: 1265-1276.

94. Sugawara K, Olson TS, Moskaluk CA, Stevens BK, Hoang S, et al. (2005) Linkage to peroxisome proliferator-activated receptor-gamma in SAMP1/ YitFc mice and in human Crohn's disease. Gastroenterology 128: 351-360.

95. Sanchez-Hidalgo M, Martin AR, Villegas I, de la Lastra CA (2007) Rosiglitazone, a PPARgamma ligand, modulates signal transduction pathways during the development of acute TNBS-induced colitis in rats. Eur J Pharmacol 562: 247-258.

96. Celinski K, Dworzanski T, Korolczuk A, Slomka M, Radej S, et al. (2011) Activated and inactivated PPARs-gamma modulate experimentally induced colitis in rats. Med Sci Monit 17: BR116-124.

97. Lewis JD, Lichtenstein GR, Deren JJ, Sands BE, Hanauer SB, et al. (2008) Rosiglitazone for active ulcerative colitis: a randomized placebo-controlled trial. Gastroenterology 134: 688-695.

98. Wang D, DuBois RN (2010) Therapeutic potential of peroxisome proliferatoractivated receptors in chronic inflammation and colorectal cancer. Gastroenterol Clin North Am 39: 697-707.

99. Dooley TP, Curto EV, Reddy SP, Davis RL, Lambert GW, et al. (2004) Regulation of gene expression in inflammatory bowel disease and correlation with IBD drugs: screening by DNA microarrays. Inflamm Bowel Dis 10: 1-14.

100. Hasler R, Feng Z, Backdahl L, Spehlmann ME, Franke A, et al. (2012) A functional methylome map of ulcerative colitis. Genome Res 22: 2130-2137.

101. Wapenaar MC, Monsuur AJ, Poell J, van 't Slot R, Meijer JW, et al. (2007) The SPINK gene family and celiac disease susceptibility. Immunogenetics 59: 349357.

102. Lakatos PL, Kiss LS, Palatka K, Altorjay I, Antal-Szalmas P, et al. (2011) Serum lipopolysaccharide-binding protein and soluble CD14 are markers of disease activity in patients with Crohn's disease. Inflamm Bowel Dis 17: 767777 .

103. Antonioli L, Fornai M, Colucci R, Awwad O, Ghisu N, et al. (2010) The blockade of adenosine deaminase ameliorates chronic experimental colitis through the recruitment of adenosine A2A and A3 receptors. J Pharmacol Exp Ther 335: 434-442.

104. Antonioli L, Fornai M, Colucci R, Ghisu N, Da Settimo F, et al. (2007) Inhibition of adenosine deaminase attenuates inflammation in experimental colitis. J Pharmacol Exp Ther 322: 435-442.

105. Hogan SP, Seidu L, Blanchard C, Groschwitz K, Mishra A, et al. (2006) Resistin-like molecule beta regulates innate colonic function: barrier integrity and inflammation susceptibility. J Allergy Clin Immunol 118: 257-268. 